\title{
两种穗型粳稻穗上不同粒位籽粒几个营养和蒸煮品质性状的比较分析
}

陈书强 ${ }^{1}$ 金峰董丹刘柏林薛菁芳张文忠 徐正进 ${ }^{*}$ 陈温福

(沈阳农业大学水稻研究所/农业部作物生理生态与遗传育种重点开放实验室 / 辽宁省北方粳稻育种重点实验室, 辽宁沈阳 110161)

摘 要: 选用典型的直立穗型和弯曲穗型粳稻品种, 研究了穗上不同粒位籽粒的几个重要营养和蒸煮品质性状差异 及其分布特点。结果表明, 穗型特征与蛋白质含量、直链淀粉含量和食味值高低无直接必然的联系, 但是对穗不同部 位间这些指标及其粒位顺序有较大影响。对 3 个直立穗型品种而言, 蛋白质含量、直链淀粉含量表现为穗下部 $>$ 中 部 > 上部, 食味值则相反, 而对 3 个弯曲穗型品种而言, 蛋白质含量、直链淀粉含量的表现规律不明显, 食味值表现 为穗上部 > 中部 > 下部; 同一稻穗不同枝梗间相比, 着生在二次枝梗上的稻米蛋白质含量相对较高、直链淀粉含量和 食味值相对较低, 而着生在一次枝梗上的稻米蛋白质含量相对较低、直链淀粉含量和食味值相对较高; 同一枝梗间的 不同着粒部位相比, 下部二次枝梗第 2、3 粒位的蛋白质含量较高、食味值较低, 中上部一次枝梗 1 6 粒位的蛋白质 含量较低、食味值较高, 而直链淀粉含量在粒位间规律不明显; 直立穗型品种单一稻穗不同粒位间的差异大于弯曲穗 型品种, 其主要原因可能是直立穗型品种着粒密度过大。

关键词：粳稻; 穗型; 粒位; 蛋白质含量; 直链淀粉含量; 食味值

\section{Comparisons of Several Nutritional and Cooking Qualities of Grains at Different Grain Positions of Panicle between Two Panicle Types of Japo- nica Rice}

CHEN Shu-Qiang, JIN Feng, DONG Dan, LIU Bai-Lin, XUE Jing-Fang, ZHANG Wen-Zhong, XU Zheng-Jin ${ }^{*}$, and CHEN Wen-Fu

(Key Laboratory of Crop Physiology, Ecology, Genetics and Breeding, Ministry of Agriculture / Key Laboratory of Northern Japonica Rice Breeding of Liaoning / Rice Institute of Shenyang Agricultural University, Shenyang 110161, Liaoning, China)

\begin{abstract}
Nutritional and taste quality are focused in rice (Oryza sativa L.) breeding for grain quality. Panicle type may have certain effect on grain quality traits. However, research in detail on grain quality difference between/within erect and curved panicle rice is not well-documented. The objective of the present study was to characterize the difference in several nutritional and cooking qualities at different seed positions in japonica rice cultivars which differ in panicle type. Three erect and three curved panicle japonica rice cultivars of similar maturity were grown in randomized block design in 2006. After maturity protein content (PC), amylose content (AC), and taste quality (TQ) of milled rice were measured. The results showed that panicle type had considerable influence on PC, AC, and TQ at the different parts of panicle, for erect panicle cultivars, PC and AC increased with the grain position from the upper to the lower parts, while TQ showed reverse trend; for curved panicle ones, PC and AC showed no regular trend, but TQ was the same as that of erect panicle cultivars. In the same panicle, the PC of secondary branches was higher than that of primary branches, while AC and TQ behaved reversely. In the same rachis branches, the 2nd and 3rd grain of secondary branch at lower part had higher PC and lower TQ, the 1st to 6th grains of primary branch at mid and upper part had lower PC and higher TQ, no rule was found for AC at different grain positions of panicle. The difference of referred quality traits at different grain positions in erect panicle was higher than that in curved panicle, resulting from higher grain density in erect panicle. Results from this study will facilitate erect panicle cultivars in rice breeding for quality in Northeast China.
\end{abstract}

Keywords: Japonica rice; Panicle type; Grain position; Protein content; Amylose content; Taste quality

基金项目: 国家自然科学基金项目(30370866); 教育部高等学校博士学科点专项科研基金项目(20050157001); 辽宁省教育厅重点实验室项目 (20060753)

作者简介: 陈书强(1976-), 男, 黑龙江阿城人, 博士研究生, 主要从事水稻产量生理与品质研究。

“通讯作者(Corresponding author): 徐正进。Tel: 024-88487183, E-mail: xuzhengjin@126.com

Received(收稿日期): 2007-07-23; Accepted(接受日期): 2007-09-27. 
东北稻区是优质粳稻的主产区, 种植面积虽小, 但是品质和产量潜力很大 ${ }^{[1]}$ 。现在东北稻区直立穗 型品种种植面积超过总面积的 $50 \%$ 以上, 直立、半 直立穗型品种的推广应用使水稻单产上了一个新台 阶 $^{[2-3]}$, 但是对于直立穗型品种营养和蒸煮食味品质 的普遍看法是稍差于弯曲穗型品种 ${ }^{[4]}$ 。因此, 改善东 北稻区直立穗型粳稻的营养和蒸煮食味品质, 对于 提高东北大米的市场竞争力和确保我国人民“口粮” 安全, 具有重要的意义。国内学者对水稻不同籽粒 的蒸煮及营养品质进行了一些研究 ${ }^{[5-8]}$ 。朱海江等 ${ }^{[5]}$ 研究表明, 直立穗型粳稻品种单一稻穗内直链淀粉 含量的粒间差异明显大于弯曲穗型品种, 直立与弯 曲两种穗型粳稻品种均表现为穗顶部籽粒的直链淀 粉含量相对较高、穗基部籽粒的直链淀粉含量相对 较低这一基本趋势。董明辉等 ${ }^{[6]}$ 认为, 穗下部一、二 次枝梗籽粒的胶稠度较低, 直链淀粉含量较高; 穗 中、上部一、二次枝梗的胶稠度较高, 直链淀粉含 量较低。在同一个枝梗上, 二次枝梗上早开花的第 1 粒的胶稠度最高, 稻穗中、上部一次枝梗迟开花的 第 2 粒的直链淀粉含量较高。蛋白含量因不同类型 品种的不同部位表现不同。

对于一个稻穗而言, 由于各枝梗上的籽粒以及 同一枝梗上不同粒位间的籽粒存在着开花时间以及 发育上的差异, 因而形成了粒重和米质性状上的差 异 $^{[9-10]}$ 。以往的研究多数是从整体上比较不同穗型粳 稻米质的差异, 但有关不同穗型粳稻穗上不同部位 及不同粒位籽粒的蒸煮及营养品质的差异及其分布 特点, 报道较少, 尤其关于不同粒位籽粒的食味研 究相对更少。本研究比较分析了粳稻不同穗型间以 及同一穗型不同部位和不同粒位籽粒间的蛋白质含 量、直链淀粉含量和食味的差异, 以期揭示其品质 变化及其粒位分布特征, 为直立穗型粳稻优质高产
育种提供一定的理论依据。

\section{1 材料与方法}

\section{1 试验设计}

试验于 2006 年在沈阳农业大学水稻研究所试 验田进行, 供试材料为不同穗型的 6 个粳稻品种, 生育期 155 158 d, 直立穗型品种 3 个, 分别为千重 浪 1 号(QCL1)、辽粳 5 号(LG5)、ZF13 [辽粳 5 号 与丰锦杂交后代(13 代)分离出的稳定纯合直立穗型 株系], 弯曲穗型品种 3 个, 分别为沈农 315 (SN315)、丰锦(FJ)、WF13 [辽粳 5 号与丰锦杂交后 代(13 代)分离出的稳定纯合弯曲穗型株系]。采用随 机区组设计, 3 次重复, 小区行长 $4 \mathrm{~m}$, 每区 8 行, 小 区面积约 $9.6 \mathrm{~m}^{2}$ 。试验地为棕壤土, 地势平坦, 肥力 中等, 井水灌溉。于 4 月 10 日左右播种, 播种量 0.2 $\mathrm{kg} \mathrm{m}^{-2}$, 营养土保温旱育苗, 5 月 20 日左右移栽, 插 植行株距为 $30 \mathrm{~cm} \times 13.3 \mathrm{~cm}$, 每穴插 1 苗。各品种 于 8 月 6 日左右开始抽穗, 8 月 10 号左右齐穗。每 公顷施尿素底肥 $150 \mathrm{~kg}$, 返青肥 $60 \mathrm{~kg}$ (5月 24 日), 分菜肥 $75 \mathrm{~kg}$ (6月 1 日), 穗肥 $60 \mathrm{~kg}$ (7 月 26 日)。磷、 钾肥以磷酸二铵 $150 \mathrm{~kg} \mathrm{hm}^{-2}$ 、硫酸钾 $112.5 \mathrm{~kg} \mathrm{hm}^{-2}$ 作底肥一次性施入。其他栽培管理同常规生产田。

\section{2 取样及测定}

于抽穗期各小区选取同日抽穗、穗型大小一致 的穗子约 800 个, 并挂纸牌标记, 观察并记载其中 一部分穗各粒位开花日期。成熟期摘取各小区的标 记穗，按穗上枝梗部位及粒位分类取样。参照 $\mathrm{Liu}^{[11]}$ 的穗部粒位划分标准(表 1), 同一枝梗上粒位划分标 准是将一次枝梗上的 6 个粒分为第 1 至第 6 个粒位, 将二次枝梗上的 3 个粒分为第 1 至第 3 个粒位。穗 上同一部位、同一粒位的籽粒合并作为一个样本, 除去空癔待测稻米品质。

表 1 供试 6 个品种的穗部粒位划分

Table 1 Classification of grain position within a panicle

\begin{tabular}{cccccc}
\hline 穗型 & 品种 & 总数 & a & \multicolumn{2}{c}{ 一次枝梗划分 Classification of primary branches } \\
\cline { 5 - 6 } Panicle type & Cultivar & Total $^{\mathrm{a}}$ & 上部 Upper & 中部 Middle & 下部 Lower \\
\hline 直立 & 千重浪 1 号 QCL1 & 15 & 5 & 5 & 5 \\
Erect panicle & 辽粳 5 号 LG5 & 13 & 4 & 5 & 4 \\
& 直立穗品系 ZF13 & 13 & 4 & 4 & 4 \\
弯曲 & 沈农 315 SN315 & 11 & 3 & 5 & 4 \\
Curved panicle & 丰锦 FJ & 13 & 4 & 4 & 4 \\
& 弯曲穗品系 WF13 & 12 & 4 & 5 \\
\hline
\end{tabular}

${ }^{\mathrm{a}}$ : 一次枝梗总数。 ${ }^{\mathrm{a}}$ : numbers of primary branches. 
均呈极显著正相关, 近红外线食味分析仪测定结果 可以用于蛋白质和直链淀粉含量的比较分析。本试 验参照该法, 用日本静冈机械制造有限公司生产的 近红外透过式 PS-500 食味分析仪测定不同粒位精米 的蛋白质、直链淀粉含量和食味值。此仪器用 300 份粳稻材料进行定标, 其中校正组 200 份, 检验组 100 份, 在波长为 850 1 $050 \mathrm{~nm}$ 的范围内, 每隔 2 $\mathrm{nm}$ 采集透射光强度, 每个样品重复扫描 10 次, 利用 WinISI 软件对光谱进行标准正常化处理和散射处理, 建模方法采用偏最小二乘法(PLS)。直链淀粉含量的 定标标准偏差(SEC)、交叉检验标准误差(SECV)和定 标决定系数(R)分别为 $1.462 、 1.634$ 和 0.861 ; 蛋白质 含量的定标标准偏差(SEC)、交叉检验标准误差 (SECV) 和定标决定系数 (R) 分别为 $0.221 、 0.256$ 和
0.988。仪器的测定范围为蛋白质含量 $4.0 \%$ 11.0\% (干基)、直链淀粉含量 15.0\% 30.0\%(总淀粉比)、食 味值 40 100 分(精米)。

\section{采用 SPSS11.5 软件进行显著性测验。}

\section{2 结果分析}

\section{1 不同穗型品种的农艺性状比较}

由表 2 可以看到, 直立穗型品种和弯曲穗型 品种在穗部性状上有显著差异, 尤其在着粒密度 和一次枝梗密度上的差异较为明显。直立穗型品 种总体表现为穗较短, 一次枝梗数和穗粒数较多, 一次枝梗密度和着粒密度较大, 粒重较小, 结实 率偏低, 产量较高; 而弯曲穗型品种则表现相反 趋势。

表 26 个粳稻品种的穗部性状

Table 2 Panicle characteristics of six japonica rice cultivars

\begin{tabular}{|c|c|c|c|c|c|c|c|c|c|c|}
\hline $\begin{array}{c}\text { 穗型 } \\
\text { Panicle type }\end{array}$ & $\begin{array}{c}\text { 品种 } \\
\text { Cultivar }\end{array}$ & $\begin{array}{c}\text { 穗数 } \\
\text { PN }\end{array}$ & $\begin{array}{c}\text { 穗长 } \\
\text { PL }\end{array}$ & $\begin{array}{c}\text { 穗粒数 } \\
\text { GN } \\
\text { (grains panicle }^{-1} \text { ) }\end{array}$ & $\begin{array}{l}\text { 一次枝 } \\
\text { 梗数 } \\
\text { PRN }\end{array}$ & $\begin{array}{c}\text { 着粒密度 } \\
\text { GD } \\
\left(\text { grains } \mathrm{cm}^{-1} \text { ) }\right.\end{array}$ & $\begin{array}{l}\text { 一次枝梗 } \\
\text { 密度 PRD } \\
\left(\mathrm{PR} \mathrm{cm}{ }^{-1}\right)\end{array}$ & $\begin{array}{c}\text { 结实率 } \\
\text { SSR } \\
(\%)\end{array}$ & $\begin{array}{c}\text { 千粒重 } \\
\text { TGW }\end{array}$ & $\begin{array}{c}\text { 产量 } \\
\text { Yield } \\
\left(\mathrm{kg} 667 \mathrm{~m}^{-2}\right)\end{array}$ \\
\hline \multirow{4}{*}{$\begin{array}{c}\text { 直立 } \\
\text { Erect panicle }\end{array}$} & QCL1 & $13.60 \mathrm{a}$ & 19.22 c & $191.10 \mathrm{a}$ & 15.07 a & 99.48 a & $0.79 \mathrm{a}$ & $92.06 \mathrm{a}$ & $23.80 \mathrm{ab}$ & 700.74 a \\
\hline & LG5 & $14.40 \mathrm{a}$ & 16.33 e & $163.40 \mathrm{~b}$ & 12.53 c & $100.30 \mathrm{a}$ & 0.78 a & $92.23 \mathrm{a}$ & 22.85 bc & $629.64 \mathrm{ab}$ \\
\hline & ZF13 & $14.40 \mathrm{a}$ & 16.53 e & 157.00 bc & 13.07 b & 95.07 a & $0.79 \mathrm{a}$ & $91.61 \mathrm{a}$ & $22.68 \mathrm{c}$ & 586.57 bc \\
\hline & 平均 Mean & 14.13 & 17.36 & 170.50 & 13.56 & 98.28 & 0.78 & 91.97 & 23.11 & 638.98 \\
\hline \multirow{4}{*}{$\begin{array}{c}\text { 弯曲 } \\
\text { Curved panicle }\end{array}$} & SN315 & $15.20 \mathrm{a}$ & $17.74 \mathrm{~d}$ & $112.90 \mathrm{e}$ & $11.13 \mathrm{e}$ & $63.76 \mathrm{~b}$ & $0.63 \mathrm{~b}$ & 92.57 a & 24.67 a & 514.40 c \\
\hline & FJ & $14.60 \mathrm{a}$ & $20.00 \mathrm{~b}$ & $138.50 \mathrm{~d}$ & $13.13 \mathrm{~b}$ & $69.35 \mathrm{~b}$ & $0.65 \mathrm{~b}$ & 93.45 a & 24.35 a & 565.94 bc \\
\hline & WF13 & $13.20 \mathrm{a}$ & 21.64 a & $149.70 \mathrm{~cd}$ & $12.00 \mathrm{~d}$ & $69.39 \mathrm{~b}$ & $0.56 \mathrm{c}$ & $92.60 \mathrm{a}$ & $23.87 \mathrm{ab}$ & 522.46 c \\
\hline & 平均 Mean & 14.33 & 19.79 & 133.70 & 12.09 & 67.50 & 0.61 & 92.88 & 24.30 & 534.26 \\
\hline
\end{tabular}

QCL1: 千重浪 1 号; LG5: 辽粳 5 号; ZF13: 直立穗品系; SN315: 沈农 315; FJ: 丰锦; WF13: 弯曲穗品系。

PN: Panicle number per hill; PL: Panicle length; GN: Grains number per panicle; PRN: Primary rachis number per panicle; GD: Grain density; PRD: Primary rachis density; SSR: Seed setting rate; TGW: 1000-grain weight.

\section{2 蛋白质含量在穗上不同部位的差异}

由表 3 可见, 供试 6 个品种的蛋白质含量在 7.55\% 8.66\%之间, 其变化趋势与品种的穗型特 征差异并无直接联系。同一品种不同枝梗的稻米 蛋白质含量, 以二次枝梗相对较高, 而一次枝梗 相对较低, 两种穗型(直立和弯曲)品种的这一表 现基本一致。值得注意的是, 穗内不同部位间蛋白 质含量的差异幅度及其粒位顺序, 却在很大程度 上与品种的穗型特征存在着密切联系。对 3 个直 立穗型品种而言, 二次和一次枝梗上的蛋白质含 量表现为下部 $>$ 中部 $>$ 上部, 差异达到显著水平。 对 3 个弯曲穗型品种来说, 二次枝梗上的蛋白质 含量也是下部 $>$ 中部 $>$ 上部, 差异达到显著水平, 而一次枝梗上的蛋白质含量表现不太规律, 但都
以中部最低。3 个直立穗型品种穗内不同部位间蛋 白质含量的差异幅度较大 $(6.54 \%$ 9.83\%), 变异系 数也较大(1.13 1.83)。而 3 个弯曲穗型品种穗内不 同部位间蛋白质含量的差异幅度较小 (7.49\% 10.16\%), 变异系数也较小 $(0.96 \sim 1.07)$ 。由 上可知, 直立穗型品种蛋白质含量上部一次枝梗 最低, 下部二次枝梗最高; 弯曲穗型品种蛋白质 含量中部一次枝梗最低, 下部二次枝梗最高; 直 立穗型品种蛋白质含量不同部位间差异大于弯曲 穗型品种。

由表 4 可见，同一品种不同粒位间相比，着生 在一次枝梗上的 6 个粒位的蛋白质含量排列顺序并 无明显规律性, 而二次枝梗上的 3 个粒位蛋白质含 量排序基本上以第 1 粒位最低, 第 3 粒位最高, 两种 
表 3 两种穗型粳稻穗上不同部位蛋白质含量的差异

Table 3 Difference of protein content in the grains at the different parts of panicle between two panicle types of japonica rice (\%)

\begin{tabular}{|c|c|c|c|c|c|c|c|}
\hline \multirow{3}{*}{$\begin{array}{c}\text { 穗上部位 } \\
\text { Part of the } \\
\text { panicle }\end{array}$} & \multicolumn{7}{|c|}{ 直立穗型 Erect panicle type } \\
\hline & \multicolumn{2}{|c|}{ QCL1 } & \multicolumn{2}{|c|}{ LG5 } & \multicolumn{2}{|c|}{ ZF13 } & \multirow{2}{*}{$\begin{array}{l}\text { 均值 }{ }^{1)} \\
\text { Mean }^{1)}\end{array}$} \\
\hline & $\begin{array}{l}\text { 平均 }{ }^{3)} \\
\text { Mean }^{3)}\end{array}$ & $C V$ & $\begin{array}{l}\text { 平均 }{ }^{3)} \\
\text { Mean }^{3)}\end{array}$ & $C V$ & $\begin{array}{l}\text { 平均 }{ }^{3)} \\
\text { Mean }^{3)}\end{array}$ & $C V$ & \\
\hline \multicolumn{8}{|c|}{ 一次枝梗 Primary branch } \\
\hline 上部 Upper & $7.54 \mathrm{c}$ & 1.26 & $6.86 \mathrm{~b}$ & 1.62 & $6.54 \mathrm{c}$ & 1.56 & $6.98 \mathrm{aB}$ \\
\hline 中部 Middle & $8.12 \mathrm{~b}$ & 0.54 & $7.13 \mathrm{~b}$ & 1.88 & $7.14 \mathrm{~b}$ & 0.82 & $7.46 \mathrm{aA}$ \\
\hline 下部 Basal & $8.28 \mathrm{a}$ & 0.35 & $7.76 \mathrm{a}$ & 2.17 & $7.67 \mathrm{a}$ & 2.07 & $7.90 \mathrm{aA}$ \\
\hline 平均 1 Mean 1 & 7.98 & & 7.25 & & 7.12 & & $7.45 \mathrm{~A}$ \\
\hline \multicolumn{8}{|c|}{ 二次枝梗 Secondary branch } \\
\hline 上部 Upper & $7.61 \mathrm{c}$ & 1.41 & $7.10 \mathrm{c}$ & 0.47 & $6.97 \mathrm{c}$ & 1.91 & $7.23 \mathrm{bB}$ \\
\hline 中部 Middle & $8.19 \mathrm{~b}$ & 1.43 & $8.71 \mathrm{~b}$ & 2.55 & $8.11 \mathrm{~b}$ & 2.41 & $8.34 \mathrm{aA}$ \\
\hline 下部 Basal & 8.66 a & 1.78 & 9.83 a & 0.34 & $8.89 \mathrm{a}$ & 2.20 & $9.13 \mathrm{aA}$ \\
\hline 平均 2 Mean 2 & 8.15 & & 8.55 & & 7.99 & & $8.23 \mathrm{~A}$ \\
\hline 平均 ${ }^{2)} \mathrm{Mean}^{2)}$ & $8.07 \mathrm{C}$ & 1.13 & $7.90 \mathrm{D}$ & 1.50 & $7.55 \mathrm{~F}$ & 1.83 & \\
\hline 变幅 Range & \multicolumn{2}{|c|}{$7.54-8.66$} & \multicolumn{2}{|c|}{$6.86-9.83$} & \multicolumn{2}{|c|}{$6.54-8.89$} & \\
\hline \multirow{3}{*}{$\begin{array}{c}\text { 穗上部位 } \\
\text { Part of the } \\
\text { panicle }\end{array}$} & \multicolumn{7}{|c|}{ 弯曲穗型 Curved panicle type } \\
\hline & \multicolumn{2}{|c|}{ SN315 } & \multicolumn{2}{|c|}{ FJ } & \multicolumn{2}{|c|}{ WF13 } & \multirow{2}{*}{$\begin{array}{l}\text { 均值 }{ }^{1)} \\
\text { Mean }^{1)}\end{array}$} \\
\hline & $\begin{array}{l}\text { 平均 }{ }^{3)} \\
\text { Mean }^{3)}\end{array}$ & $C V$ & $\begin{array}{l}\text { 平均 }{ }^{3)} \\
\text { Mean }^{3)}\end{array}$ & $C V$ & $\begin{array}{l}\text { 平均 }{ }^{3)} \\
\text { Mean }^{3)}\end{array}$ & $C V$ & \\
\hline \multicolumn{8}{|c|}{ 一次枝梗 Primary branch } \\
\hline 上部 Upper & $7.72 \mathrm{a}$ & 0.90 & $7.83 \mathrm{~b}$ & 1.18 & $8.16 \mathrm{~b}$ & 0.24 & $7.90 \mathrm{aA}$ \\
\hline 中部 Middle & $7.49 \mathrm{c}$ & 0.13 & $7.72 \mathrm{~b}$ & 0.65 & $8.16 \mathrm{~b}$ & 1.01 & 7.79 aA \\
\hline 下部 Basal & $7.60 \mathrm{~b}$ & 0.38 & $8.08 \mathrm{a}$ & 0.98 & $8.34 \mathrm{a}$ & 0.31 & $8.01 \mathrm{aA}$ \\
\hline 平均 1 Mean 1 & 7.60 & & 7.88 & & 8.22 & & $7.90 \mathrm{~A}$ \\
\hline \multicolumn{8}{|c|}{ 二次枝梗 Secondary branch } \\
\hline 上部 Upper & $7.68 \mathrm{~b}$ & 1.40 & $8.01 \mathrm{c}$ & 0.87 & $8.14 \mathrm{c}$ & 0.85 & $7.94 \mathrm{aA}$ \\
\hline 中部 Middle & $7.82 \mathrm{~b}$ & 1.37 & $8.84 \mathrm{~b}$ & 1.15 & 9.02 b & 2.16 & $8.56 \mathrm{abA}$ \\
\hline 下部 Basal & $8.42 \mathrm{a}$ & 1.60 & $9.68 \mathrm{a}$ & 1.73 & $10.16 \mathrm{a}$ & 1.87 & $9.42 \mathrm{bA}$ \\
\hline 平均 2 Mean 2 & 7.97 & & 8.84 & & 9.11 & & $8.64 \mathrm{~A}$ \\
\hline 平均 ${ }^{2)} \mathrm{Mean}^{2)}$ & $7.79 \mathrm{E}$ & 0.96 & $8.36 \mathrm{~B}$ & 1.09 & $8.66 \mathrm{~A}$ & 1.07 & \\
\hline 变幅 Range & \multicolumn{2}{|c|}{$7.49-8.42$} & \multicolumn{2}{|c|}{$7.72-9.68$} & \multicolumn{2}{|c|}{$8.14-10.16$} & \\
\hline
\end{tabular}

QCL1: 千重浪 1 号; LG5: 辽粳 5 号; ZF13: 直立穗品系; SN315: 沈农 315; FJ: 丰锦; WF13: 弯曲穗品系。

1) 数据后不同的大写字母表示不同穗型间同一部位上在 $5 \%$ 水平上的差异显著性, ${ }^{2)}$ 数据后不同的大写字母表示不同品种间在 $5 \%$ 水平上的差异显著性, ${ }^{3)}$ 数据后不同的小写字母表示同一品种不同部位间在 $5 \%$ 水平上的差异显著性。

${ }^{1)}$ Data followed by a different uppercase letter indicated significant difference at the 0.05 probability level for PC in the grains at the same panicle position between two panicle types. ${ }^{2)}$ Data followed by a different uppercase letter indicated significant difference at the 0.05 probability level for PC in the grains between different cultivars. ${ }^{3)}$ Data followed by a different lowercase letter indicated significant difference at the 0.05 probability level for PC in the grains between different parts of the same cultivars.

穗型(直立和弯曲)品种的这一表现基本一致。供试 6 个品种穗不同部位的粒位间蛋白质含量的分布特点 及其粒位间的相对变化规律, 在很大程度上与品种 的穗型特征存在着一定的联系。对 3 个直立穗型品 种而言, 穗一次枝梗上不同粒位蛋白质含量分布特 点为下部 1 6 粒位 > 中部 1 6 粒位 > 上部 1 6 粒位, 二次枝梗上则为下部 1 3 粒位 > 中部 1 3 粒位 > 上
部 1 3 粒位, 其他粒位相对于上部一次枝梗第 1 粒 位的蛋白质含量的相对变化值是按照穗内粒位的排 序从上向下逐渐升高的，以下部二次枝梗第 2 粒位 最高。对 3 个弯曲穗型品种来讲, 穗一次枝梗上不 同粒位蛋白质含量分布特点为下部 $1 \sim 6$ 粒位 $>$ 上部 $1 \sim 6$ 粒位 > 中部 1 6 粒位, 二次枝梗上则为下部 1 3 粒位 > 中部 1 3 粒位 >上部 1 3 粒位; 其他粒位相 
对于上部一次枝梗第 1 粒位的蛋白质含量的相对变 化规律不如直立穗型品种明显, 但是穗二次枝梗上 的第 2、3 粒位的相对值较高, 且按位置排序是从上 向下逐渐升高的, 以下部二次枝梗第 3 粒位最高。 上述表明，同一稻穗不同籽粒的蛋白质含量变化与
其相应的粒位有关，直立穗型品种下部二次枝梗 2、 3 粒位蛋白质含量相对较高, 上部一次枝梗 1 6 粒位 相对较低; 弯曲穗型品种下部二次枝梗 $2 、 3$ 粒位蛋 白质含量相对较高, 而中部一次枝梗 1 6 粒位相对 较低。

表 4 两种穗型粳稻穗上不同粒位蛋白质含量的差异

Table 4 Difference of protein content in the grains between different grain positions in two panicle types of japonica rice (\%)

\begin{tabular}{|c|c|c|c|c|c|c|c|c|c|c|c|}
\hline \multirow{2}{*}{$\begin{array}{c}\text { 穗上部位 } \\
\text { Part of the panicle }\end{array}$} & \multirow{2}{*}{$\begin{array}{c}\text { 粒位 } \\
\text { Posi- } \\
\text { tion } \\
\end{array}$} & \multirow{2}{*}{$\begin{array}{c}\text { 直立穗型 } \\
\text { QCL1 }\end{array}$} & \multicolumn{2}{|c|}{ Erect panicle type (EP) } & \multirow{2}{*}{$\begin{array}{l}\text { 均值 }{ }^{1)} \\
\text { Mean }{ }^{1)}\end{array}$} & \multirow{2}{*}{$\begin{array}{c}\text { 相对值 }{ }^{\mathrm{a})} \\
\mathrm{RR}^{\mathrm{a})}\end{array}$} & \multirow{2}{*}{$\begin{array}{c}\text { 弯曲穗型 } \\
\text { SN315 } \\
\end{array}$} & \multicolumn{2}{|c|}{ Curved panicle type (CP) } & \multirow{2}{*}{$\begin{array}{l}\text { 均值 } \\
\text { Mean }^{1)}\end{array}$} & \multirow{2}{*}{$\begin{array}{c}\text { 相对值 } \\
\mathrm{RR}^{\mathrm{a})}\end{array}$} \\
\hline & & & LG5 & ZF13 & & & & FJ & WF13 & & \\
\hline \multicolumn{12}{|l|}{ 上部 Upper } \\
\hline 一次枝梗 & 1 & $7.47 \mathrm{a}$ & $6.40 \mathrm{~d}$ & $6.30 \mathrm{c}$ & $6.72 \mathrm{aB}$ & 100.00 & $7.77 \mathrm{a}$ & $8.07 \mathrm{~b}$ & 8.10 abc & $7.98 \mathrm{abA}$ & 100.00 \\
\hline \multirow[t]{5}{*}{ Primary branch } & 2 & $7.53 \mathrm{a}$ & $6.63 \mathrm{~cd}$ & $6.77 \mathrm{bc}$ & 6.98 aA & 103.77 & $7.83 \mathrm{a}$ & $7.60 \mathrm{c}$ & $8.00 \mathrm{bc}$ & $7.81 \mathrm{abA}$ & 97.87 \\
\hline & 3 & $7.60 \mathrm{a}$ & $6.83 \mathrm{bc}$ & $6.70 \mathrm{bc}$ & $7.04 \mathrm{aA}$ & 104.76 & $7.70 \mathrm{ab}$ & 7.77 bc & $8.13 \mathrm{abc}$ & $7.87 \mathrm{abA}$ & 98.58 \\
\hline & 4 & $7.60 \mathrm{a}$ & $7.03 \mathrm{ab}$ & $6.67 \mathrm{bc}$ & $7.10 \mathrm{aA}$ & 105.60 & $7.67 \mathrm{ab}$ & $7.90 \mathrm{~b}$ & $8.30 \mathrm{ab}$ & $7.96 \mathrm{abA}$ & 99.71 \\
\hline & 5 & $7.63 \mathrm{a}$ & $7.13 \mathrm{ab}$ & $6.47 \mathrm{c}$ & $7.08 \mathrm{aA}$ & 105.26 & $7.60 \mathrm{ab}$ & $7.90 \mathrm{~b}$ & $8.17 \mathrm{abc}$ & $7.89 \mathrm{abA}$ & 98.87 \\
\hline & 6 & $7.40 \mathrm{a}$ & $7.10 \mathrm{ab}$ & $6.37 \mathrm{c}$ & $6.96 \mathrm{aB}$ & 103.47 & $7.77 \mathrm{a}$ & 7.77 bc & $8.23 \mathrm{ab}$ & $7.92 \mathrm{abA}$ & 99.29 \\
\hline 二次枝梗 & 1 & $7.60 \mathrm{a}$ & $6.93 \mathrm{abc}$ & $6.40 \mathrm{c}$ & $6.98 \mathrm{aA}$ & 103.77 & $7.37 \mathrm{~b}$ & $7.57 \mathrm{c}$ & $7.87 \mathrm{c}$ & $7.60 \mathrm{bA}$ & 95.28 \\
\hline \multirow[t]{2}{*}{ Secondary branch } & 2 & $7.67 \mathrm{a}$ & $7.07 \mathrm{ab}$ & $7.17 \mathrm{ab}$ & $7.30 \mathrm{aB}$ & 108.63 & $7.77 \mathrm{a}$ & $8.47 \mathrm{a}$ & $8.37 \mathrm{a}$ & $8.20 \mathrm{aA}$ & 102.80 \\
\hline & 3 & $7.57 \mathrm{a}$ & $7.30 \mathrm{a}$ & 7.33 a & $7.40 \mathrm{aA}$ & 110.06 & $7.90 \mathrm{a}$ & $8.00 \mathrm{~b}$ & 8.20 abc & $8.03 \mathrm{abA}$ & 100.67 \\
\hline \multicolumn{12}{|l|}{ 中部 Middle } \\
\hline 一次枝梗 & 1 & $7.83 \mathrm{c}$ & $6.93 \mathrm{~cd}$ & $6.83 \mathrm{c}$ & $7.20 \mathrm{cA}$ & 107.04 & $7.77 \mathrm{bc}$ & $7.70 \mathrm{c}$ & $8.10 \mathrm{c}$ & $7.86 \mathrm{bA}$ & 98.45 \\
\hline \multirow[t]{5}{*}{ Primary branch } & 2 & $7.83 \mathrm{c}$ & $6.87 \mathrm{~d}$ & 7.17 bc & 7.29 сA & 108.43 & $7.67 \mathrm{bcd}$ & $7.57 \mathrm{c}$ & $8.20 \mathrm{c}$ & $7.81 \mathrm{bA}$ & 97.91 \\
\hline & 3 & $8.20 \mathrm{ab}$ & $7.00 \mathrm{~cd}$ & $6.90 \mathrm{c}$ & $7.37 \mathrm{cA}$ & 109.57 & 7.50 cde & $7.70 \mathrm{c}$ & $8.17 \mathrm{c}$ & $7.79 \mathrm{bA}$ & 97.62 \\
\hline & 4 & $8.23 \mathrm{ab}$ & $7.23 \mathrm{~cd}$ & $7.37 \mathrm{~b}$ & 7.61 bcA & 113.19 & $7.33 \mathrm{e}$ & $7.73 \mathrm{c}$ & $8.13 \mathrm{c}$ & $7.73 \mathrm{bA}$ & 96.87 \\
\hline & 5 & $8.13 \mathrm{~b}$ & 7.37 bc & $7.37 \mathrm{~b}$ & $7.62 \mathrm{cbA}$ & 113.39 & $7.37 \mathrm{de}$ & $7.80 \mathrm{c}$ & $8.27 \mathrm{c}$ & $7.81 \mathrm{bA}$ & 97.91 \\
\hline & 6 & 8.47 a & 7.37 bc & $7.20 \mathrm{bc}$ & 7.68 abcA & 114.23 & $7.30 \mathrm{e}$ & $7.80 \mathrm{c}$ & $8.10 \mathrm{c}$ & $7.73 \mathrm{bA}$ & 96.91 \\
\hline 二次枝梗 & 1 & 8.07 bc & $7.67 \mathrm{~b}$ & $7.47 \mathrm{~b}$ & 7.74 abcA & 115.07 & 7.50 cde & $7.77 \mathrm{c}$ & $8.23 \mathrm{c}$ & $7.83 \mathrm{bA}$ & 98.16 \\
\hline \multirow[t]{2}{*}{ Secondary branch } & 2 & $8.27 \mathrm{ab}$ & $9.37 \mathrm{a}$ & $8.37 \mathrm{a}$ & 8.67 aA & 128.95 & $8.10 \mathrm{a}$ & 10.10 a & $9.73 \mathrm{a}$ & $9.31 \mathrm{aA}$ & 116.67 \\
\hline & 3 & $8.23 \mathrm{ab}$ & $9.10 \mathrm{a}$ & $8.50 \mathrm{a}$ & $8.61 \mathrm{abA}$ & 128.06 & $7.87 \mathrm{ab}$ & $8.67 \mathrm{~b}$ & $9.10 \mathrm{~b}$ & $8.55 \mathrm{abA}$ & 107.10 \\
\hline \multicolumn{12}{|l|}{ 下部 Basal } \\
\hline 一次枝梗 & 1 & 8.43 abc & $7.53 \mathrm{c}$ & $7.27 \mathrm{c}$ & $7.74 \mathrm{bA}$ & 115.17 & $7.30 \mathrm{c}$ & $7.83 \mathrm{~d}$ & $8.07 \mathrm{~b}$ & $7.73 \mathrm{bA}$ & 96.91 \\
\hline \multirow[t]{5}{*}{ Primary branch } & 2 & $8.17 \mathrm{c}$ & $7.73 \mathrm{c}$ & 7.53 bc & $7.81 \mathrm{bA}$ & 116.16 & 7.57 bc & $8.70 \mathrm{~d}$ & $8.37 \mathrm{~b}$ & $8.21 \mathrm{bA}$ & 102.92 \\
\hline & 3 & 8.27 bc & 7.67 c & $7.83 \mathrm{~b}$ & $7.92 \mathrm{bA}$ & 117.85 & $7.80 \mathrm{~b}$ & $8.27 \mathrm{c}$ & $8.40 \mathrm{~b}$ & $8.16 \mathrm{bA}$ & 102.21 \\
\hline & 4 & $8.33 \mathrm{abc}$ & $7.80 \mathrm{bc}$ & $7.63 \mathrm{bc}$ & $7.92 \mathrm{bA}$ & 117.80 & $7.57 \mathrm{bc}$ & $7.77 \mathrm{~d}$ & $8.37 \mathrm{~b}$ & $7.90 \mathrm{bA}$ & 99.04 \\
\hline & 5 & $8.37 \mathrm{abc}$ & $7.93 \mathrm{bc}$ & $7.90 \mathrm{~b}$ & $8.07 \mathrm{bA}$ & 119.98 & $7.73 \mathrm{~b}$ & $7.93 \mathrm{~cd}$ & $8.43 \mathrm{~b}$ & $8.03 \mathrm{bA}$ & 100.63 \\
\hline & 6 & $8.13 \mathrm{c}$ & $7.90 \mathrm{bc}$ & $7.83 \mathrm{~b}$ & $7.95 \mathrm{bA}$ & 118.29 & $7.63 \mathrm{bc}$ & $7.97 \mathrm{~cd}$ & $8.43 \mathrm{~b}$ & $8.01 \mathrm{bA}$ & 100.38 \\
\hline 二次枝梗 & 1 & $8.60 \mathrm{ab}$ & $8.23 \mathrm{~b}$ & $7.83 \mathrm{~b}$ & $8.22 \mathrm{bA}$ & 122.26 & $7.70 \mathrm{~b}$ & $7.97 \mathrm{~cd}$ & $8.50 \mathrm{~b}$ & $8.06 \mathrm{bA}$ & 100.96 \\
\hline \multirow[t]{2}{*}{ Secondary branch } & 2 & $8.63 \mathrm{ab}$ & 10.73 a & $9.53 \mathrm{a}$ & $9.63 \mathrm{aA}$ & 143.23 & $8.80 \mathrm{a}$ & 10.53 а & 10.87 a & $10.07 \mathrm{aA}$ & 126.15 \\
\hline & 3 & 8.73 a & $10.53 \mathrm{a}$ & $9.30 \mathrm{a}$ & $9.52 \mathrm{aA}$ & 141.60 & 8.77 a & 10.53 a & $11.10 \mathrm{a}$ & $10.13 \mathrm{aA}$ & 126.98 \\
\hline 变幅 Range & & 7.4-8.7 & $6.4-10.7$ & $6.3-9.5$ & $6.7-9.6$ & & 7.3-8.3 & 7.6-10.5 & 7.9-11.1 & $7.6-10.1$ & \\
\hline
\end{tabular}

QCL1: 千重浪 1 号; LG5: 辽粳 5 号; ZF13: 直立穗品系; SN315: 沈农 315; FJ: 丰锦; WF13: 弯曲穗品系。

不同的小写字母表示同一品种在同一部位上不同粒位间 $5 \%$ 水平的差异显著性, ${ }^{1)}$ 数据后不同的大写字母表示不同穗型同一部 位间在 5\%水平上的差异显著性， a) 表示其他粒位相对一次枝梗上第 1 粒位的相对百分值。

Values followed by a different lowercase letter are significantly different at 0.05 probability level for PC between grain positions of the same parts in the same cultivars. ${ }^{1)}$ Data followed by a different uppercase letter are significantly different at 0.05 probability level for PC in the grains at the same parts between two panicle types. ${ }^{\text {a) }}$ Relative ratio of protein content for other grains to the grain 1 on the primary branches at the upper part of panicle. RR: relative ratio.

\section{3 直链淀粉含量在穗上不同部位的差异}

由表 5 可见, 供试 6 个品种的直链淀粉含量在 17.42\% 18.37\%之间, 其变化趋势与品种的穗型特 征差异并无直接联系。同一品种不同枝梗间相比, 着生在一次枝梗上的稻米直链淀粉含量相对较高,
而二次枝梗相对较低, 两种穗型(直立和弯曲)品种 的这一表现基本一致。值得注意的是，穗不同部位 间直链淀粉含量的差异幅度及其粒位顺序, 却在很 大程度上与品种的穗型特征存在着密切联系。对 3 个直立穗型品种而言, 二次和一次枝梗上的直链淀 
粉含量表现为下部 $\geq$ 中部 $>$ 上部, 差异达到显著水 平。对 3 个弯曲穗型品种来说, 二次和一次枝梗上 的直链淀粉含量上、中、下 3 部分表现不太规律, 因 品种而异。3 个直立穗型品种穗不同部位间直链淀 粉含量的差异幅度较大(17.00\% 18.49\%), 变异系数 也较大(0.45 0.87)。而 3 个弯曲穗型品种穗不同部位
间直链淀粉含量的差异幅度较小 $(17.80 \%$ 18.56\%), 变异系数也较小 $(0.28 \sim 0.64)$ 。可以看出, 直立穗型品 种直链淀粉含量以下部一次枝梗较高, 上部和中部 二次枝梗较低; 弯曲穗型品种直链淀粉含量以中部 一次枝梗较高, 下部二次枝梗较低; 直立穗型品种 直链淀粉含量不同部位间差异大于弯曲穗型品种。

表 5 两种穗型粳稻穗上不同部位直链淀粉含量的差异

Table 5 Difference of amylose content in the grains at the different parts of panicle between two panicle types of japonica rice (\%)

\begin{tabular}{|c|c|c|c|c|c|c|c|}
\hline \multirow{4}{*}{$\begin{array}{c}\text { 穗上部位 } \\
\text { Part of the } \\
\text { panicle }\end{array}$} & \multicolumn{7}{|c|}{ 直立穗型 Erect panicle type } \\
\hline & \multicolumn{2}{|c|}{ QCL1 } & \multicolumn{2}{|c|}{ LG5 } & \multicolumn{2}{|c|}{ ZF13 } & \multirow{3}{*}{$\begin{array}{l}\text { 均值 }{ }^{1)} \\
\text { Mean }^{1)}\end{array}$} \\
\hline & \multirow{2}{*}{$\begin{array}{l}\text { 平均 }{ }^{3)} \\
\text { Mean }^{3)}\end{array}$} & \multirow{2}{*}{$C V$} & 平均 ${ }^{3)}$ & \multirow{2}{*}{$C V$} & 平均 ${ }^{3)}$ & \multirow{2}{*}{$C V$} & \\
\hline & & & Mean $^{3)}$ & & Mean $^{3)}$ & & \\
\hline \multicolumn{8}{|c|}{ 一次枝梗 Primary branch } \\
\hline 上部 Upper & $17.93 \mathrm{~b}$ & 0.28 & 17.98 a & 0.44 & $17.25 \mathrm{~b}$ & 1.21 & $17.72 \mathrm{aA}$ \\
\hline 中部 Middle & 18.39 a & 0.60 & 18.09 a & 0.42 & $17.44 \mathrm{~b}$ & 0.36 & $17.97 \mathrm{aA}$ \\
\hline 下部 Basal & 18.49 a & 0.29 & 18.08 a & 0.27 & 17.93 a & 0.81 & $18.17 \mathrm{aA}$ \\
\hline 平均 1 Mean 1 & 18.27 & & 18.05 & & 17.54 & & $17.95 \mathrm{~A}$ \\
\hline \multicolumn{8}{|c|}{ 二次枝梗 Secondary branch } \\
\hline 上部 Upper & $17.96 \mathrm{~b}$ & 0.39 & 17.68 a & 0.66 & $17.34 \mathrm{a}$ & 0.89 & $17.66 \mathrm{aA}$ \\
\hline 中部 Middle & $18.16 \mathrm{a}$ & 0.74 & $17.84 \mathrm{a}$ & 0.57 & $17.00 \mathrm{~b}$ & 0.90 & $17.67 \mathrm{aA}$ \\
\hline 下部 Basal & $18.20 \mathrm{a}$ & 0.37 & 17.73 a & 0.68 & $17.56 \mathrm{a}$ & 1.05 & $17.83 \mathrm{aA}$ \\
\hline 平均 2 Mean 2 & 18.10 & & 17.75 & & 17.30 & & $17.72 \mathrm{~A}$ \\
\hline 平均 ${ }^{2)} \mathrm{Mean}^{2)}$ & $18.19 \mathrm{~B}$ & 0.45 & $17.90 \mathrm{D}$ & 0.51 & $17.42 \mathrm{E}$ & 0.87 & \\
\hline 变幅 Range & \multicolumn{2}{|c|}{ 17.93-18.49 } & \multicolumn{2}{|c|}{ 17.68-18.09 } & \multicolumn{2}{|c|}{$17.00-17.93$} & \\
\hline \multirow{4}{*}{$\begin{array}{c}\text { 穗上部位 } \\
\text { Part of the } \\
\text { panicle }\end{array}$} & \multicolumn{7}{|c|}{ 弯曲穗型 Curved panicle type } \\
\hline & \multicolumn{2}{|c|}{ SN315 } & \multicolumn{2}{|c|}{ FJ } & \multicolumn{2}{|c|}{ WF13 } & \multirow{3}{*}{$\begin{array}{l}\text { 均值 }{ }^{1)} \\
\text { Mean }^{1)}\end{array}$} \\
\hline & 平均 ${ }^{3)}$ & $C V$ & 平均 ${ }^{3)}$ & $C V$ & 平均 ${ }^{3)}$ & $C V$ & \\
\hline & Mean $^{3)}$ & CV & Mean $^{3)}$ & $C V$ & Mean $^{3)}$ & CV & \\
\hline \multicolumn{8}{|c|}{ 一次枝梗 Primary branch } \\
\hline 上部 Upper & $17.80 \mathrm{~b}$ & 0.28 & 18.33 a & 0.33 & $18.56 \mathrm{a}$ & 0.23 & $18.23 \mathrm{aA}$ \\
\hline 中部 Middle & $18.07 \mathrm{a}$ & 0.09 & 18.33 a & 0.16 & $18.48 \mathrm{ab}$ & 0.16 & $18.29 \mathrm{aA}$ \\
\hline 下部 Basal & $18.02 \mathrm{a}$ & 0.28 & 18.33 a & 0.29 & $18.40 \mathrm{~b}$ & 0.65 & $18.25 \mathrm{aA}$ \\
\hline 平均 1 Mean 1 & 17.96 & & 18.33 & & 18.48 & & $18.26 \mathrm{~A}$ \\
\hline \multicolumn{8}{|c|}{ 二次枝梗 Secondary branch } \\
\hline 上部 Upper & $17.88 \mathrm{~b}$ & 0.11 & $18.12 \mathrm{~b}$ & 0.11 & 18.49 a & 0.75 & $18.16 \mathrm{aA}$ \\
\hline 中部 Middle & $18.22 \mathrm{a}$ & 0.38 & $18.01 \mathrm{~b}$ & 0.28 & $18.32 \mathrm{ab}$ & 0.56 & $18.19 \mathrm{aA}$ \\
\hline 下部 Basal & 18.10 a & 0.55 & 18.29 a & 0.69 & $17.96 \mathrm{~b}$ & 1.51 & $18.11 \mathrm{aA}$ \\
\hline 平均 2 Mean 2 & 18.07 & & 18.14 & & 18.26 & & $18.15 \mathrm{~A}$ \\
\hline 平均 ${ }^{2)} \mathrm{Mean}^{2)}$ & $18.01 \mathrm{C}$ & 0.28 & 18.24 B & 0.31 & 18.37 A & 0.64 & \\
\hline 变幅 Range & \multicolumn{2}{|c|}{$17.80-18.22$} & \multicolumn{2}{|c|}{$18.01-18.33$} & \multicolumn{2}{|c|}{$17.96-18.56$} & \\
\hline
\end{tabular}

QCL1: 千重浪 1 号; LG5: 辽粳 5 号; ZF13: 直立穗品系; SN315: 沈农 315; FJ: 丰锦; WF13: 弯曲穗品系。

1) 数据后不同的大写字母表示不同穗型间同一部位上在 $5 \%$ 水平上的差异显著性, ${ }^{2)}$ 数据后不同的大写字母表示不同品种间在 $5 \%$ 水平上的差异显著性, ${ }^{3}$ 数据后不同的小写字母表示同一品种不同部位间在 $5 \%$ 水平上的差异显著性。

${ }^{1)}$ Data followed by a different uppercase letter are significantly different at the 0.05 probability level for AC in the grains at the same panicle position between two panicle types. ${ }^{2)}$ Data followed by a different uppercase letter are significantly different at the 0.05 probability level for AC in the grains between different cultivars. ${ }^{3)}$ Data followed by a different lowercase letter are significantly different at the 0.05 probability level for AC in the grains between different parts in the same cultivars.

由表 6 可见, 同一品种枝梗上不同粒位间相比, 着生在一次枝梗上的 6 个粒位的直链淀粉含量基本 上以第 6 粒位较高, 第 1 粒位较低, 其他粒位排列顺 序没有规律性; 而二次枝梗上 3 个粒位直链淀粉含
量以第 3 粒位较高, 第 2 粒位较低, 两种穗型(直立 和弯曲)品种的这一表现基本一致。供试 6 个品种穗 内不同部位的粒位间直链淀粉含量的分布特点及其 粒位间的相对变化规律, 在很大程度上与品种的穗 
型特征存在着一定的联系。对 3 个直立穗型品种而 言, 穗内一次枝梗上不同粒位直链淀粉含量分布特 点为下部 1 6 粒位 > 中部 1 6 粒位 > 上部 1 6 粒位, 二次枝梗上不同粒位直链淀粉含量分布特点为下部 $1 \sim 2$ 粒位 $>$ 上部和中部 1 2 粒位, 其他粒位相对于上 部一次枝梗第 1 粒位的直链淀粉含量的相对变化值, 是按照穗内粒位位置的排序从上向下逐渐升高的, 但上部和中部二次枝梗的第 2 粒位却是降低的。对 3 个弯曲穗型品种来讲, 穗内一次枝梗上不同粒位 直链淀粉含量分布特点以中部 $1 \sim 6$ 粒位较高, 上部 和下部 $1 \sim 6$ 粒位较低, 二次枝梗上不同粒位直链淀
粉含量分布特点以中部 $1 、 3$ 粒位较高, 上部和下部 1、3 粒位较低; 其他粒位相对于上部一次枝梗第 1 粒位的直链淀粉含量的相对变化规律不如直立穗型 品种明显, 但是穗下部二次枝梗上的第 $2 、 3$ 粒位的 相对值较低。这也说明同一稻穗不同籽粒间的直链 淀粉含量变化与其颖花在穗上的开花顺序有关，直 立穗型品种下部一次枝梗 1 6 粒位直链淀粉含量相 对较高, 上部和中部二次枝梗 $1 \sim 3$ 粒位相对较低; 弯曲穗型品种以中部一次枝梗 1 6 粒位直链淀粉含 量相对较高, 上部和下部二次枝梗 $1 \sim 3$ 粒位相对 较低。

表 6 两种穗型粳稻穗上不同粒位直链淀粉含量的差异

Table 6 Difference of amylose content in the grains between different grain positions in two panicle types of japonica rice (\%)

\begin{tabular}{|c|c|c|c|c|c|c|c|c|c|c|c|}
\hline \multirow{2}{*}{$\begin{array}{c}\text { 穗上部位 } \\
\text { Part of the panicle }\end{array}$} & \multirow{2}{*}{$\begin{array}{l}\text { 粒位 } \\
\text { Posi- } \\
\text { tion }\end{array}$} & \multicolumn{3}{|c|}{ 直立穗型 Erect panicle type } & \multirow{2}{*}{$\begin{array}{l}\text { 均值 }^{1)} \\
\text { Mean }^{1)}\end{array}$} & \multirow{2}{*}{$\begin{array}{c}\text { 相对值 }{ }^{a)} \\
\mathrm{RR}^{\mathrm{a})}\end{array}$} & \multicolumn{3}{|c|}{ 弯曲穗型 Curved panicle type } & \multirow{2}{*}{$\begin{array}{l}\text { 均值 } \\
{ }^{1)} \\
\text { Mean }^{1)}\end{array}$} & \multirow{2}{*}{$\begin{array}{c}\text { 相对值 }{ }^{\text {a) }} \\
\mathrm{RR}^{\text {a) }}\end{array}$} \\
\hline & & QCL1 & LG5 & ZF13 & & & SN315 & FJ & WF13 & & \\
\hline \multicolumn{12}{|l|}{ 上部 Upper } \\
\hline \multirow{6}{*}{$\begin{array}{l}\text { 一次枝梗 } \\
\text { Primary branch }\end{array}$} & 1 & $17.77 \mathrm{c}$ & $17.63 \mathrm{c}$ & $17.20 \mathrm{~b}$ & $17.53 \mathrm{aA}$ & 100.00 & $17.50 \mathrm{~d}$ & $18.23 \mathrm{a}$ & $18.57 \mathrm{abc}$ & $18.10 \mathrm{aA}$ & 100.00 \\
\hline & 2 & 17.83 bc & $17.93 \mathrm{abc}$ & $17.37 \mathrm{ab}$ & $17.71 \mathrm{aA}$ & 101.01 & $18.07 \mathrm{a}$ & $18.20 a b$ & $18.53 \mathrm{abc}$ & $18.27 \mathrm{aA}$ & 100.92 \\
\hline & 3 & 17.93 abc & $17.97 \mathrm{abc}$ & $17.37 \mathrm{ab}$ & $17.76 \mathrm{aA}$ & 101.27 & 17.97 abc & 18.43 a & $18.53 \mathrm{abc}$ & $18.31 \mathrm{aA}$ & 101.17 \\
\hline & 4 & $18.07 \mathrm{ab}$ & $17.93 \mathrm{abc}$ & $17.20 \mathrm{~b}$ & $17.73 \mathrm{aA}$ & 101.14 & 17.87 abc & $18.30 \mathrm{a}$ & 18.57 abc & $18.24 \mathrm{aA}$ & 100.80 \\
\hline & 5 & 17.83 bc & $18.17 \mathrm{ab}$ & $17.17 \mathrm{~b}$ & $17.72 \mathrm{aA}$ & 101.08 & $17.70 \mathrm{bcd}$ & $18.40 \mathrm{a}$ & $18.37 \mathrm{c}$ & $18.16 \mathrm{aA}$ & 100.31 \\
\hline & 6 & 18.13 a & 18.23 a & $17.20 \mathrm{~b}$ & $17.86 \mathrm{aA}$ & 101.84 & $17.70 \mathrm{bcd}$ & $18.43 \mathrm{a}$ & $18.80 \mathrm{a}$ & $18.31 \mathrm{aA}$ & 101.17 \\
\hline \multirow{3}{*}{$\begin{array}{l}\text { 二次枝梗 } \\
\text { Secondary branch }\end{array}$} & 1 & $17.87 \mathrm{abc}$ & $17.77 \mathrm{bc}$ & $17.23 \mathrm{ab}$ & $17.62 \mathrm{aA}$ & 100.51 & $17.67 \mathrm{~cd}$ & $18.00 \mathrm{bc}$ & $18.30 \mathrm{c}$ & $17.99 \mathrm{aA}$ & 99.39 \\
\hline & 2 & $18.00 \mathrm{abc}$ & $17.27 \mathrm{~d}$ & $17.00 \mathrm{~b}$ & $17.42 \mathrm{aA}$ & 99.37 & $18.00 \mathrm{ab}$ & $17.97 \mathrm{c}$ & $18.47 \mathrm{bc}$ & $18.14 \mathrm{aA}$ & 100.25 \\
\hline & 3 & $18.00 \mathrm{abc}$ & 18.00 abc & 17.80 a & $17.93 \mathrm{aA}$ & 102.28 & 17.97 abc & $18.40 \mathrm{a}$ & $18.70 \mathrm{ab}$ & 18.36 aA & 101.41 \\
\hline \multicolumn{12}{|l|}{ 中部 Middle } \\
\hline \multirow{6}{*}{$\begin{array}{l}\text { 一次枝梗 } \\
\text { Primary branch }\end{array}$} & 1 & $17.97 \mathrm{~d}$ & $17.90 \mathrm{ab}$ & $17.10 \mathrm{bc}$ & $17.66 \mathrm{aA}$ & 100.70 & $17.87 \mathrm{~d}$ & $18.20 \mathrm{a}$ & 18.43 a & 18.17 aA & 100.37 \\
\hline & 2 & $18.43 \mathrm{abc}$ & $17.70 \mathrm{bc}$ & 17.73 a & $17.96 \mathrm{aA}$ & 102.41 & $18.13 \mathrm{bc}$ & 18.33 a & 18.57 a & $18.34 \mathrm{aA}$ & 101.35 \\
\hline & 3 & $18.40 \mathrm{abc}$ & $18.10 a b$ & $17.30 \mathrm{ab}$ & $17.93 \mathrm{aA}$ & 102.28 & $18.23 \mathrm{ab}$ & $18.33 \mathrm{a}$ & $18.50 \mathrm{a}$ & 18.36 aA & 101.41 \\
\hline & 4 & $18.43 \mathrm{abc}$ & $18.30 \mathrm{a}$ & $17.40 \mathrm{ab}$ & $18.04 \mathrm{aA}$ & 102.92 & 18.13 bc & 18.33 a & $18.40 \mathrm{a}$ & $18.29 \mathrm{aA}$ & 101.04 \\
\hline & 5 & $18.50 \mathrm{ab}$ & $18.20 \mathrm{ab}$ & $17.50 \mathrm{ab}$ & $18.07 \mathrm{aA}$ & 103.04 & 18.07 bcd & $18.40 \mathrm{a}$ & 18.53 a & $18.33 \mathrm{aA}$ & 101.29 \\
\hline & 6 & 18.63 a & 18.33 a & $17.60 \mathrm{ab}$ & $18.19 \mathrm{aA}$ & 103.74 & $17.97 \mathrm{~cd}$ & $18.40 \mathrm{a}$ & 18.47 a & $18.28 \mathrm{aA}$ & 100.98 \\
\hline \multirow{3}{*}{$\begin{array}{l}\text { 一次忟㛹 } \\
\text { Secondary branch }\end{array}$} & 1 & $18.20 \mathrm{bcd}$ & $18.07 \mathrm{ab}$ & $17.37 \mathrm{ab}$ & $17.88 \mathrm{aA}$ & 101.96 & $18.03 \mathrm{bcd}$ & 18.37 a & 18.43 a & $18.28 \mathrm{aA}$ & 100.98 \\
\hline & 2 & $18.07 \mathrm{~cd}$ & $17.37 \mathrm{c}$ & $16.57 \mathrm{c}$ & $17.33 \mathrm{aA}$ & 98.86 & $18.40 \mathrm{a}$ & $17.27 \mathrm{~b}$ & $18.00 \mathrm{~b}$ & 17.89 aA & 98.83 \\
\hline & 3 & $18.20 \mathrm{bcd}$ & $18.10 \mathrm{ab}$ & $17.07 \mathrm{bc}$ & $17.79 \mathrm{aA}$ & 101.46 & $18.23 \mathrm{ab}$ & $18.40 \mathrm{a}$ & 18.53 a & $18.39 \mathrm{aA}$ & 101.60 \\
\hline \multicolumn{12}{|l|}{ 下部 Basal } \\
\hline \multirow{6}{*}{$\begin{array}{l}\text { 一次枝梗 } \\
\text { Primary branch }\end{array}$} & 1 & 18.57 a & 17.80 bc & $17.47 \mathrm{c}$ & $17.94 \mathrm{abA}$ & 102.34 & $17.67 \mathrm{~b}$ & $18.13 \mathrm{~b}$ & $18.33 \mathrm{ab}$ & $18.04 \mathrm{aA}$ & 99.69 \\
\hline & 2 & 18.47 a & $17.73 \mathrm{~cd}$ & 17.77 bc & $17.99 \mathrm{abA}$ & 102.60 & 18.03 a & $18.33 \mathrm{ab}$ & $18.27 \mathrm{ab}$ & $18.21 \mathrm{aA}$ & 100.61 \\
\hline & 3 & $18.50 \mathrm{a}$ & $17.97 \mathrm{abc}$ & $18.00 \mathrm{ab}$ & $18.16 \mathrm{abA}$ & 103.55 & $18.20 \mathrm{a}$ & $18.27 \mathrm{ab}$ & $18.40 \mathrm{a}$ & $18.29 \mathrm{aA}$ & 101.04 \\
\hline & 4 & 18.57 a & $18.17 \mathrm{abc}$ & $18.00 \mathrm{ab}$ & $18.24 \mathrm{aA}$ & 104.06 & 18.17 a & $18.27 \mathrm{ab}$ & $18.33 \mathrm{ab}$ & 18.26 aA & 100.86 \\
\hline & 5 & $18.50 \mathrm{a}$ & 18.43 a & $18.07 \mathrm{ab}$ & $18.33 \mathrm{aA}$ & 104.56 & 18.07 a & $18.50 \mathrm{a}$ & 18.37 a & $18.31 \mathrm{aA}$ & 101.17 \\
\hline & 6 & $18.37 \mathrm{ab}$ & $18.37 \mathrm{ab}$ & $18.30 \mathrm{a}$ & $18.34 \mathrm{aA}$ & 104.63 & $18.00 \mathrm{a}$ & $18.47 \mathrm{a}$ & $18.70 \mathrm{a}$ & $18.39 \mathrm{aA}$ & 101.60 \\
\hline \multirow{3}{*}{$\begin{array}{l}\text { 二次枝梗 } \\
\text { Secondary branch }\end{array}$} & 1 & $18.53 \mathrm{a}$ & 18.17 abc & $17.80 \mathrm{abc}$ & $18.17 \mathrm{abA}$ & 103.61 & 18.13 a & $18.30 \mathrm{ab}$ & $18.30 \mathrm{ab}$ & $18.24 \mathrm{aA}$ & 100.80 \\
\hline & 2 & $17.97 \mathrm{c}$ & $17.23 \mathrm{~d}$ & $17.47 \mathrm{c}$ & $17.56 \mathrm{bA}$ & 100.13 & $18.00 \mathrm{a}$ & $18.47 \mathrm{a}$ & $17.73 \mathrm{c}$ & $18.07 \mathrm{aA}$ & 99.82 \\
\hline & 3 & 18.10 bc & 17.80 bc & $17.40 \mathrm{c}$ & $17.77 \mathrm{abA}$ & 101.33 & 18.17 a & $18.10 \mathrm{~b}$ & 17.83 bc & $18.03 \mathrm{aA}$ & 99.63 \\
\hline 变幅 Range & & $17.8-18.6$ & $17.2-18.4$ & $16.6-18.3$ & $17.3-18.3$ & & $17.5-18.4$ & $17.3-18.5$ & $17.7-18.8$ & $17.9-18.4$ & \\
\hline
\end{tabular}

QCL1: 千重浪 1 号; LG5: 辽粳 5 号; ZF13: 直立穗品系; SN315：沈农 315; FJ：丰锦; WF13: 弯曲穗品系。

不同的小写字母表示同一品种在同一部位上不同粒位间 $5 \%$ 水平的差异显著性。1) 数据后不同的大写字母表示不同穗型同一部 位间在 5\%水平上的差异显著性, a) 表示其他粒位相对一次枝梗上第 1 粒位的相对百分值。

Values followed by a different lowercase letter are significantly different at the 0.05 probability level for AC between grain positions of the same parts in the same cultivars. ${ }^{1)}$ Data followed by a different uppercase letter are significantly different at the 0.05 probability level for $\mathrm{AC}$ in the grains at the same parts between the two panicle types. ${ }^{\text {a) }}$ Relative ratio of amylose content for other grains to the grain 1 on the primary branches at the upper part of panicle. RR: relative ratio.

\section{4 食味值在穗上不同部位的差异} 由表 7 可见，供试 6 个品种的食味值在 73.83\%
85.64\%之间，其变化趋势与品种的穗型特征差异 并无直接联系。同一品种不同枝梗间相比，着生在 
二次枝梗上的稻米食味值相对较低, 而一次枝梗 相对较高, 两种穗型(直立和弯曲)品种的这一表 现基本一致。值得注意的是，穗不同部位间食味值 的差异幅度及其粒位顺序，却在很大程度上与品 种的穗型特征存在着密切联系。对 3 个直立穗型 品种而言，一次和二次枝梗上的食味值表现为上 部 > 中部 >下部, 差异达到显著水平。对 3 个弯曲 穗型品种来说, 一次枝梗上的食味值表现中部和 上部 >下部，二次枝梗上的食味值也表现上部 >
中部 > 下部, 差异达到显著水平。3 个直立穗型品 种穗内不同部位间食味值的变异幅度较大, 变异 系数在 1.64 4.59 之间。而 3 个弯曲穗型品种穗不 同部位间食味值的变异幅度较小, 变异系数在 1.33 3.28 之间。由此可以看出, 直立穗型品种食 味值以上部一次枝梗最高, 下部二次枝梗最低; 弯曲穗型品种食味值以中部一次枝梗最高, 下部 二次枝梗最低; 直立穗型品种食味值不同部位间 变异大于弯曲穗型品种。

表 7 两种穗型粳稻穗上不同部位食味值的差异

Table 7 Difference of taste quality in the grains at the different panicle parts between the two panicle types of japonica rice (\%)

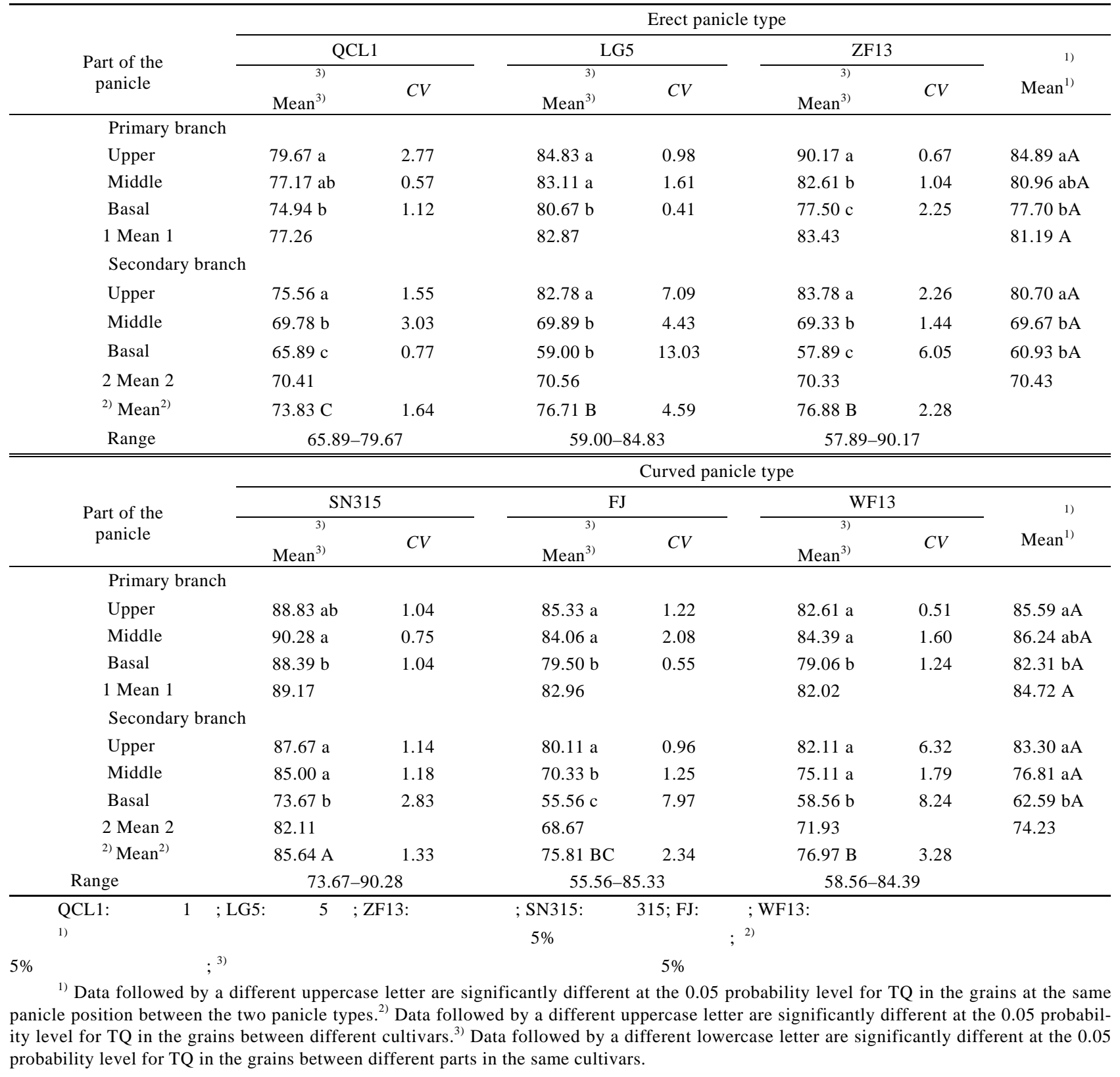

由表 8 可见，同一品种同一枝梗上不同粒位间 相比，着生在一次枝梗上的 6 个粒位的食味值以第 1 
粒位较高, 其他粒位排列顺序并无明显规律性, 而 二次枝梗上的 3 个粒位食味值均以第 1 粒位最高, 第 2 粒位最低, 两种穗型(直立和弯曲)品种的这一表 现基本一致。同一品种的穗一次枝梗上不同粒位食 味值分布特点是下部 1 6 粒位 < 中部 1 6 粒位 < 上 部 1 6 粒位, 二次枝梗上则为下部 1 3 粒位 <中部 $1 \sim 3$ 粒位 <上部 1 3 粒位, 两种穗型品种表现一致。 供试 6 个品种穗内不同粒位间食味值的相对变化规 律, 与品种的穗型特征存在着一定关系。对 3 个直 立穗型品种而言, 其他粒位对上部一次枝梗第 1 粒
位的食味值的相对变化值是按照穗内粒位的位置排 序由上向下逐渐降低的, 以下部二次枝梗第 2 粒位 为最低。对 3 个弯曲穗型品种来讲, 其他粒位对上 部一次枝梗第 1 粒位的食味值的相对变化不太规律, 但是穗内二次枝梗上的第 2、3 粒位的相对值较低, 且按位置排序是从上向下逐渐降低的, 以下部二次 枝梗第 2 粒位最低。上述表明，同一稻穗内不同籽 粒间的食味值变化与其颖花在穗上的开花顺序有密 切联系, 两种穗型品种都以下部二次枝梗 $2 、 3$ 粒位 食味值相对较低, 上部一次枝梗 1 6 粒位相对较高。

表 8 两种穗型粳稻穗上不同粒位食味值的差异

Table 8 Difference of taste quality in the grains between different grain positions in the two panicle types of japonica rice (\%)

\begin{tabular}{|c|c|c|c|c|c|c|c|c|c|c|c|}
\hline \multirow{2}{*}{$\begin{array}{c}\text { 穗上部位 } \\
\text { Part of the panicle }\end{array}$} & \multirow{2}{*}{$\begin{array}{l}\text { 粒位 } \\
\text { Posi- } \\
\text { tion }\end{array}$} & \multicolumn{3}{|c|}{ 直立穗型 Erect panicle type } & \multirow{2}{*}{$\begin{array}{l}\text { 均值 }{ }^{1)} \\
\text { Mean }^{1)}\end{array}$} & \multirow{2}{*}{$\begin{array}{c}\text { 相对值 }^{\text {a) }} \\
\mathrm{RR}^{\mathrm{a})}\end{array}$} & \multicolumn{3}{|c|}{ 弯曲穗型 Curved panicle type } & \multirow{2}{*}{$\begin{array}{l}\text { 均值 }{ }^{1)} \\
\text { Mean }^{1)}\end{array}$} & \multirow{2}{*}{$\begin{array}{c}\text { 相对值 }{ }^{a)} \\
\mathrm{RR}^{\mathrm{a})}\end{array}$} \\
\hline & & QCL1 & LG5 & ZF13 & & & SN315 & FJ & WF13 & & \\
\hline \multicolumn{12}{|l|}{ 上部 Upper } \\
\hline 一次枝梗 & 1 & 84.67 a & 88.00 a & 93.67 a & $88.78 \mathrm{aA}$ & 100.00 & 89.33 a & $86.33 \mathrm{ab}$ & 81.67 a & $85.78 \mathrm{aA}$ & 100.00 \\
\hline \multirow[t]{5}{*}{ Primary branch } & 2 & $79.00 \mathrm{ab}$ & 85.00 a & $89.67 \mathrm{ab}$ & $84.56 \mathrm{aA}$ & 95.24 & 88.67 a & $85.33 \mathrm{ab}$ & 83.67 a & 85.89 aA & 100.13 \\
\hline & 3 & $79.33 \mathrm{ab}$ & 86.33 a & $88.00 \mathrm{abc}$ & $84.56 \mathrm{aA}$ & 95.24 & 88.67 a & $86.33 \mathrm{ab}$ & $84.00 \mathrm{a}$ & $86.33 \mathrm{aA}$ & 100.65 \\
\hline & 4 & $79.33 \mathrm{ab}$ & 82.00 a & $89.67 \mathrm{ab}$ & 83.67 aA & 94.24 & 89.67 a & 87.00 a & 82.67 a & 86.44 aA & 100.78 \\
\hline & 5 & $80.00 \mathrm{ab}$ & 84.67 a & $89.00 \mathrm{ab}$ & $84.56 \mathrm{aA}$ & 95.24 & 88.33 a & $84.67 \mathrm{ab}$ & $81.00 \mathrm{a}$ & 84.67 aA & 98.70 \\
\hline & 6 & $75.67 \mathrm{~b}$ & 83.00 a & $91.00 \mathrm{ab}$ & $83.22 \mathrm{aA}$ & 93.74 & 88.33 a & 82.33 bc & 82.67 a & $84.44 \mathrm{aA}$ & 98.45 \\
\hline 二次枝梗 & 1 & $78.00 \mathrm{ab}$ & 82.33 a & 87.00 bcd & $82.44 \mathrm{aA}$ & 92.87 & 89.67 a & $84.67 \mathrm{ab}$ & 84.67 a & $86.33 \mathrm{aA}$ & 100.65 \\
\hline \multirow[t]{2}{*}{ Secondary branch } & 2 & $75.33 \mathrm{~b}$ & 82.33 a & $81.33 \mathrm{~d}$ & $79.67 \mathrm{aA}$ & 89.74 & 85.67 a & $77.00 \mathrm{~d}$ & 80.67 a & $81.11 \mathrm{aA}$ & 94.56 \\
\hline & 3 & $73.33 \mathrm{~b}$ & 83.67 a & $83.00 \mathrm{~cd}$ & $80.00 \mathrm{aA}$ & 90.11 & 87.67 a & 78.67 cd & 81.00 a & $82.44 \mathrm{aA}$ & 96.11 \\
\hline \multicolumn{12}{|l|}{ 中部 Middle } \\
\hline 一次枝梗 & 1 & $78.33 \mathrm{ab}$ & 83.33 a & 82.67 а & $81.44 \mathrm{aA}$ & 91.74 & $89.33 \mathrm{~b}$ & 83.67 a & 86.00 a & $86.33 \mathrm{aA}$ & 100.65 \\
\hline \multirow[t]{5}{*}{ Primary branch } & 2 & $80.00 \mathrm{a}$ & 82.67 a & 83.67 a & $82.11 \mathrm{aA}$ & 92.49 & $89.00 \mathrm{~b}$ & 83.67 a & $85.00 \mathrm{a}$ & $85.89 \mathrm{aA}$ & 100.13 \\
\hline & 3 & $75.33 \mathrm{~b}$ & 82.67 a & 80.33 a & $79.44 \mathrm{aA}$ & 89.49 & $92.67 \mathrm{ab}$ & 86.67 a & 84.67 a & $88.00 \mathrm{aA}$ & 102.59 \\
\hline & 4 & $77.33 \mathrm{ab}$ & 83.00 a & 83.00 a & $81.11 \mathrm{aA}$ & 91.36 & $89.00 \mathrm{~b}$ & 84.67 a & $84.00 \mathrm{a}$ & 85.89 aA & 100.13 \\
\hline & 5 & $77.33 \mathrm{ab}$ & 82.00 a & 82.67 a & 80.67 aA & 90.86 & $92.00 \mathrm{ab}$ & 84.67 a & 83.67 a & 86.78 aA & 101.17 \\
\hline & 6 & $74.67 \mathrm{~b}$ & 85.00 a & 83.33 а & $81.00 \mathrm{aA}$ & 91.24 & $89.67 \mathrm{~b}$ & 81.00 a & 83.00 a & $84.56 \mathrm{aA}$ & 98.58 \\
\hline 二次枝梗 & 1 & $76.33 \mathrm{ab}$ & 82.67 a & 79.33 a & $79.44 \mathrm{aA}$ & 89.49 & 93.67 a & 83.33 a & 84.67 a & $87.22 \mathrm{aA}$ & 101.68 \\
\hline \multirow[t]{2}{*}{ Secondary branch } & 2 & $63.33 \mathrm{~d}$ & $60.67 \mathrm{~b}$ & $62.33 \mathrm{~b}$ & $62.11 \mathrm{bA}$ & 69.96 & $82.00 \mathrm{c}$ & $63.67 \mathrm{~b}$ & 67.33 c & $71.00 \mathrm{bA}$ & 82.77 \\
\hline & 3 & 69.67 c & $66.33 \mathrm{~b}$ & $66.33 \mathrm{~b}$ & $67.44 \mathrm{bA}$ & 75.97 & 79.33 c & $64.00 \mathrm{~b}$ & $73.33 \mathrm{~b}$ & $72.22 \mathrm{bA}$ & 84.20 \\
\hline \multicolumn{12}{|l|}{ 下部 Basal } \\
\hline 一次枝梗 & 1 & 77.67 a & 87.67 a & 81.33 a & $82.22 \mathrm{aA}$ & 92.62 & $88.67 \mathrm{ab}$ & 83.67 a & 82.33 a & $84.89 \mathrm{aA}$ & 98.96 \\
\hline \multirow[t]{5}{*}{ Primary branch } & 2 & $74.00 \mathrm{ab}$ & 77.00 a & 75.00 a & $75.33 \mathrm{aA}$ & 84.86 & $85.33 \mathrm{~b}$ & $74.33 \mathrm{~b}$ & 75.00 a & $78.22 \mathrm{aA}$ & 91.19 \\
\hline & 3 & $76.33 \mathrm{ab}$ & 76.67 a & 76.33 a & $76.44 \mathrm{aA}$ & 86.11 & $88.33 \mathrm{ab}$ & $76.00 \mathrm{ab}$ & 77.67 a & $80.67 \mathrm{aA}$ & 94.04 \\
\hline & 4 & $73.33 \mathrm{~b}$ & 79.67 a & 77.33 a & $76.78 \mathrm{aA}$ & 86.48 & $90.00 \mathrm{a}$ & $80.67 \mathrm{ab}$ & $79.33 \mathrm{a}$ & $83.33 \mathrm{aA}$ & 97.15 \\
\hline & 5 & $74.67 \mathrm{ab}$ & 82.00 a & 78.33 а & $78.33 \mathrm{aA}$ & 88.24 & $89.67 \mathrm{ab}$ & $81.33 \mathrm{ab}$ & 79.33 a & $83.44 \mathrm{aA}$ & 97.28 \\
\hline & 6 & $73.67 \mathrm{~b}$ & 81.00 a & 76.67 a & $77.11 \mathrm{aA}$ & 86.86 & $88.33 \mathrm{ab}$ & $81.00 \mathrm{ab}$ & 80.67 a & $83.33 \mathrm{aA}$ & 97.15 \\
\hline 二次枝梗 & 1 & $73.00 \mathrm{~b}$ & 77.33 a & $74.00 \mathrm{a}$ & $74.78 \mathrm{aA}$ & 84.23 & $85.33 \mathrm{~b}$ & $80.00 \mathrm{ab}$ & $78.00 \mathrm{a}$ & $81.11 \mathrm{aA}$ & 94.56 \\
\hline \multirow[t]{2}{*}{ Secondary branch } & 2 & 62.33 c & $49.67 \mathrm{~b}$ & $49.67 \mathrm{~b}$ & $53.89 \mathrm{bA}$ & 60.70 & 67.33 c & $41.00 \mathrm{c}$ & $48.33 \mathrm{~b}$ & 52.22 bA & 60.88 \\
\hline & 3 & 62.33 c & $50.00 \mathrm{~b}$ & $50.00 \mathrm{~b}$ & $54.11 \mathrm{bA}$ & 60.95 & 68.33 c & $45.67 \mathrm{c}$ & $49.33 \mathrm{~b}$ & $54.44 \mathrm{bA}$ & 63.47 \\
\hline 变幅 Range & & $62.3-84.7$ & 49.7-88.0 & 49.7-93.7 & 53.9-88.8 & & 67.3-93.7 & $41.0-87.0$ & $48.3-86.0$ & 52.2-88.0 & \\
\hline
\end{tabular}

QCL1: 千重浪 1号; LG5: 辽粳 5 号; ZF13: 直立穗品系; SN315: 沈农 315; FJ: 丰锦; WF13: 弯曲穗品系。

不同的小写字母表示同一品种在同一部位上不同粒位间 $5 \%$ 水平的差异显著性; ${ }^{11}$ 数据后不同的大写字母表示不同穗型同一部 位间在 5\%水平上的差民显著性; ${ }^{\text {a) }}$ 表示其他粒位相对一次枝梗上第 1 粒位的相对百分值。

Values followed by a different lowercase letter are significantly different at the 0.05 probability level for TQ between grain positions of the same parts in the same cultivars. ${ }^{1)}$ Data followed by a different uppercase letter are significantly different at the 0.05 probability level for TQ in the grains at the same parts between two panicle types. ${ }^{\text {a) }}$ Relative ratio of taste quality for other grains to the grain 1 on the primary branches at the upper part of panicle. RR: relative ratio. 


\section{3 讨论}

关于不同穗型品种稻米营养与蒸煮品质的问题, 国内学者的研究结论尚不完全一致, 吕文彦等 ${ }^{[4]}$ 认 为辽宁省直立穗型品种蒸煮食味品质相对较差。徐 大勇等 ${ }^{[13]}$ 研究表明江淮稻区直立穗型品种较半直立 和弯曲穗型品种胶稠度相对较硬、蛋白质含量较高, 而直链淀粉含量在 3 种类型间没有明显差异。左晓 旭等 ${ }^{[14]}$ 认为直立穗型品种(EA6)食味品质显著优于弯 曲穗型品种(秀水 11), 表明直立穗型品种经改良其米 质有可能达到甚至超过弯曲穗型品种。徐正进等 ${ }^{[15]}$ 认为直立穗型性状本身与米质性状并无直接的联系, 完全有可能育成优质高产的直立穗型品种。本研究 结果表明, 品种间的蛋白质含量、直链淀粉含量和 食味值差异显著, 而水稻品种的穗型特征与品种间 的蛋白质含量、直链淀粉含量和食味值高低并无直 接必然联系, 这与徐正进和左晓旭等人的研究结论 一致。以上研究结果不相一致的原因除供试材料不 同外，与试验环境不同有关，应该利用代表性品种 系统地进行研究。

Wang 等 ${ }^{[16]}$ 研究表明, 紧穗型品种优势粒与劣 势粒之间在严白粒率和直链淀粉含量上的差异比散 穗型品种要大。Kato ${ }^{[17]}$ 认为通常大穗型或直立穗型 品种同一穗内在粒重和品质上的差异比小穗型或弯 曲穗型品种大。Liu 等 ${ }^{[11]}$ 研究发现, 同一穗内不同粒 位籽粒在粒重、 4 种可溶性蛋白质和总蛋白质含量上 有较大差异。本研究也表明, 粳稻穗型特征虽然与 品种间的蛋白质含量、直链淀粉含量和食味值高低 无直接联系, 但是对其穗不同部位间籽粒的蛋白质 含量、直链淀粉含量和食味值有较大影响, 直立穗 型品种单一稻穗内不同部位间的差异要大于弯曲穗 型品种。已有研究报道, 由于直立穗型品种(或紧穗 型品种)的着粒密度较大, 导致穗内优、劣势粒间淀 粉合成关键酶(腺苷二磷酸葡萄糖焦磷酸化酶、可溶 性淀粉分支酶、淀粉分支酶和颗粒结合型淀粉合成 酶)活性和 5 种激素(吲哚乙酸、赤霉素、玉米素核 甘、脱落酸和乙烯)含量差异较大, 致使优、劣势粒 间的库强度产生较大差异, 最终造成劣势粒在胚乳 细胞增殖速率和细胞数目、灌浆速率、籽粒充实度、 粒重和品质等方面均明显不及优势粒 ${ }^{[16,18-19]}$ 。本试 验中所用的直立穗型品种着粒密度显著大于弯曲穗 型品种, 这可能是导致其与弯曲穗型品种在不同部 位间的蛋白质含量、直链淀粉含量和食味值产生差 异的主要原因之一。Wang 等 ${ }^{[16]}$ 认为通过调节源库关
系减小直立穗型(或紧穗型)品种穗内不同部位间品 质的差异可能是提高其品质的一种有效途径。

关于不同粒位籽粒的营养与蒸煮品质, 现有的 认识也不完全一致。通常一次枝梗或上部枝梗上的 籽粒比二次枝梗或下部枝梗上的籽粒有较高的粒重 和较好的蒸煮品质 ${ }^{[20-23]}$ 。张小明等 ${ }^{[8]}$ 、朱海江等 ${ }^{[5]}$ 和刘立军等 ${ }^{[7]}$ 研究表明, 水稻穗顶部籽粒、一次枝梗 籽粒和先开花籽粒的直链淀粉含量相对较高、穗基 部籽粒、二次枝梗籽粒和后开花的第 2 粒的直链淀 粉含量相对较低。而董明辉等 ${ }^{[6]}$ 认为穗下部一、二 次枝梗籽粒的直链淀粉含量较高, 上部一、二次枝 梗的直链淀粉含量较低; 在同一个枝梗上, 穗子中、 上部一次枝梗迟开花的第 2 粒的直链淀粉含量较 高。本研究表明, 两种穗型品种直链淀粉含量是一 次枝梗上籽粒高于二次枝梗上籽粒, 但在部位和粒 位间规律不太明显; 而蛋白质含量和食味值变化与 其穗内相应的粒位有密切关系，两种穗型蛋白质含 量都是下部二次枝梗 2、3 粒位相对较高, 上中部一 次枝梗 1 6 粒位相对较低; 食味值则正相反。上述 结果说明稻米粒位间的营养与蒸煮品质与开花顺序 有一定关系。

一些学者发现，早开花的强势粒，一般灌浆启 动早, 灌浆速率和胚乳细胞增殖速率较大, 胚乳细 胞多, 籽粒充实好, 粒重较高 ${ }^{[24-26]}$ 。稻穗内籽粒间的 发育和品质形成的差异主要是由于穗内籽粒光合产 物分配不同造成的, 而光合产物的分配是与籽粒的 库容量大小相关的 ${ }^{[27-28]}$ 。植物激素不仅调节籽粒库 的大小，也调节胚乳细胞分裂和增大，控制同化物

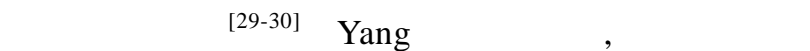
早期, 早开花的优势粒中吲哚乙酸、赤霉素、玉米 素核苷、脱落酸含量和脱落酸与 1-氨基环丙烷-1-羧 酸的浓度比例比晚开花的劣势粒高, 而乙烯和 1-氨基 环丙烷-1-羒酸含量水平较低, 胚乳细胞分裂速度和灌 浆速率与吲哚乙酸、赤霉素、玉米素核苷、脱落酸含 量和脱落酸与乙烯浓度比呈显著正相关 ${ }^{[19,31-32]}$ 。早开 花的强势粒和晚开花的弱势粒中与淀粉合成相关酶 (腺苷二磷酸葡萄糖焦磷酸化酶、可溶性淀粉分支 酶、淀粉分支酶和颗粒结合型淀粉合成酶)的活性也 不同 ${ }^{[17,28,33]}$ ，杨建昌等 ${ }^{[33]}$ 和 Wang 等 ${ }^{[16]}$ 发现，早开花 的强势粒, 灌浆期籽粒中腺苷二磷酸葡萄糖焦磷酸 化酶、可溶性淀粉分支酶、淀粉分支酶和颗粒结合 型淀粉合成酶的活性均显著高于迟开花的弱势粒。 赵步洪等 ${ }^{[34]}$ 报道, 上述几个酶的活性与稻米的蒸煮 
食味品质有密切关系。Umemoto 等 ${ }^{[35]}$ 也认为劣势粒 的充实和品质较差主要是由于低酶活性造成的。 Tsutomu 等 ${ }^{[36]}$ 研究发现, 花后前 $5 \mathrm{~d}$ 内, 劣势粒比优 势粒中的已糖/蔗糖浓度比率较低, 酸性转化酶活性 较高, 编码碳水化合物代谢酶的基因没有充分表 达。上述研究结果说明, 同一稻穗内不同籽粒间营 养和蒸煮品质的差异可能与其不同粒位的同化物供 应、胚乳细胞增殖速率、激素含量、淀粉合成相关 酶活性以及编码碳水化合物代谢酶基因的表达 有关。

营养与蒸煮品质在穗上分布的差异主要是由于 强弱势粒间的品质差异造成的, 所以增加穗上强势 粒的比例, 可以减小这种差异。已有研究表明, 二次 枝梗籽粒偏向穗轴中上部分布有利于改善二次枝梗 籽粒结实性, 减少穗轴不同部位籽粒结实性及品质 的差异, 是协调大穗型品种产量与品质矛盾的有效

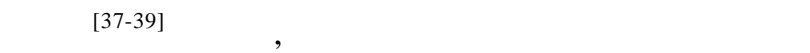
颈维管束发达, 一次枝梗数偏多和二次枝梗偏向穗 轴中上部分布的品种, 将有助于提高水稻结实率和 减少穗内不同粒位间品质的差异, 这是北方粳稻高 产优质育种遗传改良的有效途径。在栽培上通过外 喷激素等化控方式或者通过调节源库关系, 提高根 系活力、增加同化物的供应强度、促进胚乳细胞的 分裂、提高籽粒中激素含量和与淀粉合成有关的关 键酶活性、促进编码碳水化合物代谢酶基因的表达, 使水稻活秆成熟, 有可能减少直立穗型品种营养和 蒸煮品质在同一稻穗内不同籽粒间的差异, 并有望 改善直立穗型品种籽粒的充实度和稻米品质。

通常直链淀粉和蛋白质含量较低有利于改善食 味 ${ }^{[40-41]}$ 。本试验结果也显示(表 9), 粒位间食味值与 蛋白质含量呈极显著负相关 $\left(-0.824^{* *}\right)$, 与直链淀粉 含量相关不显著 (0.075), 这可能是食味值与蛋白质 含量在粒位间相对应的主要原因。本研究中弯曲穗

表 9 同一稻穗内不同粒位间蛋白质含量、直链淀粉含量和食味 值的相关性

Table 9 Correlations of protein content, amylose content, and taste quality at the different positions within a panicle in rice

\begin{tabular}{|c|c|c|c|}
\hline $\begin{array}{c}\text { 品质性状 } \\
\text { Quality character }\end{array}$ & $\begin{array}{c}\text { 蛋白质含量 } \\
\text { Protein content }\end{array}$ & $\begin{array}{c}\text { 直链淀粉含量 } \\
\text { Amylose content }\end{array}$ & $\begin{array}{c}\text { 食味值 } \\
\text { Taste quality }\end{array}$ \\
\hline $\begin{array}{l}\text { 蛋白质含量 } \\
\text { Protein content }\end{array}$ & 1 & & \\
\hline $\begin{array}{l}\text { 直链淀粉含量 } \\
\text { Amylose content }\end{array}$ & $0.218^{* *}$ & 1 & \\
\hline $\begin{array}{l}\text { 食味值 } \\
\text { Taste quality }\end{array}$ & $-0.824^{* *}$ & 0.075 & 1 \\
\hline
\end{tabular}

型品种虽然蛋白质含量都高于直立穗型品种, 但是 食味值也高于直立穗型品种, 这说明食味品质不只 由蛋白质含量决定，而是蛋白质含量、直链淀粉含 量和其他食味指标共同作用的结果。随着施氮量的 增加，水稻籽粒中的蛋白质含量有不同程度增加 ${ }^{[6]}$ 。 因此, 在辽宁省当前普遍水稻施氮肥较高水平的情 况下，在水稻生长后期通过确定合理的氮肥用量, 以降低蛋白质含量对食味品质负面影响, 应该是改 善食味品质的有效途径。

\section{4 结论}

辽宁省粳稻的穗型特征与品种间的蛋白质含 量、直链淀粉含量和食味值高低并无直接必然的联 系, 但对其穗内不同部位间这些指标及其粒位顺序 影响较大, 直立穗型品种单一稻穗内不同粒位间的 差异大于弯曲穗型品种, 直立穗型品种着粒密度过 大可能是其主要原因之一。同一稻穗内不同籽粒间 的蛋白质含量、直链淀粉含量和食味值高低与其颖 花在穗上的开花顺序有密切联系, 两种穗型(直立和 弯曲)品种都是下部二次枝梗第 2、3 粒位品质相对 较差, 上中部一次枝梗 1 6 粒位品质相对较好。

\section{References}

[1] Chen W-F(陈温福), Pan W-B(潘文博), Xu Z-J(徐正进). Current situation and trends in production of japonica rice in China. $J$ Shenyang Agric Univ (沈阳农业大学学报), 2006, 37(6): 801-805 (in Chinese with English abstract)

[2] Kong X-D(孔祥斗), Zhang H-X(张洪熙), Liu X-J(刘晓静). Development of economical characters of japonica variety and prospects of high yield breeding. J Jiangsu Agric Sci (江苏农业 科学), 1997, (3): 2-16 (in Chinese)

[3] Jin J-S(金建松), Xia Y-L(夏有龙). Develop principles of japonica rice in Jiangsu province and its techniques. J Jiangsu Agric Sci (江苏农业科学), 1998, (1): 6-10 (in Chinese)

[4] Lü W-Y(吕文彦), Cao P(曹萍), Shao G-J(邵国军). Study on quality characters of main rice varieties in Liaoning province. $J$ Liaoning Agric Sci (辽宁农业科学), 1997, (5): 7-11 (in Chinese)

[5] Zhu H-J(朱海江), Cheng F-M(程方民), Wang F(王丰), Zhong L-J(钟连进), Zhao N-C(赵宁春), Liu Z-H(刘正辉). Difference in amylose content variation of rice grains and its position distribution within a panicle between two panicle types of japonica cultivars. Chin J Rice Sci (中国水稻科学), 2004, 18(4): 321-325 (in Chinese with English abstract)

[6] Dong M-H(董明辉), Sang D-Z(桑大志), Wang P(王朋), Wang $\mathrm{X}-\mathrm{M}$ (王学明), Yang J-C(杨建昌). Changes in cooking and nutritional qualities of grains at different positions within a rice panicle under different nitrogen levels. Chin J Rice Sci (中国水稻科 学), 2006, 20(4): 389-395 (in Chinese with English abstract)

[7] Liu L-J(刘立军), Xie G-H(谢光辉). Effect of flowering sequence of spikelets on endosperm cells and grain quality of rice. Chin J Rice Sci (中国水稻科学), 2001, 15 (2): 119-124 (in Chinese with English abstract)

[8] Zhang X-M(张小明), Shi C-H(石春海), Horiuchi H, Tomita K. Bao G-L(鲍根良), Feng S-Y(冯水英), Ye S-H(叶胜海). The differences of grain amylose contents in different panicle parts of 
japonica rice variety. Acta Agron Sin (作物学报), 2002, 28 (1): 99-103 (in Chinese with English abstract)

[9] Zhang P-L(张佩莲), Zhong X-H(钟旭华), Zeng X-J(曾宪江), $\mathrm{Xu} Y-\mathrm{Q}$ (徐益群). A study on the difference in the chalk degree of the grains in a panicle. Acta Agric Univ Jiangxiensis (江西农业 大学学报), 1995, 17(4): 396-399 (in Chinese with English abstract)

[10] Zhong X-H(钟旭华), Zhang P-L(张佩莲), Zeng X-J(曾宪江), $\mathrm{Xu} Y-Q$ (徐益群). The difference in chalkiness between superior and inferior grains and the relation between chalkiness and grain weight. Acta Agric Univ Jiangxiensis (江西农业大学学报), 1996, 18(2): 154-159 (in Chinese with English abstract)

[11] Liu Z H, Cheng F M, Cheng W D, Zhang G P. Positional variations in phytic acid and protein content within a panicle of $j a-$ ponica rice. J Cereal Sci, 2005, 41: 297-303

[12] Xu Z-J(徐正进), Chen W-F(陈温福)，Ma D-R(马殿荣)，Wu X-D(吴晓冬), Zheng Y-Y(郑暗炎), Wang J-Y(王嘉宇). Relationship between eating quality and other quality characters of rice in Liaoning. Acta Agron Sin (作物学报), 2005, 31(8): 1092-1094 (in Chinese with English abstract)

[13] Xu D-Y(徐大勇), Du Y(杜永), Fang Z-W(方兆伟), Pan Q-M(潘 启民), Yang J-C(杨建昌). Zhu Q-S(朱庆森). Comparison on main agronomical and quality characters between japonica cultivars with different panicle types in Jiang-Huai area. Acta Agron Sin (作物学报), 2006, 32(3): 379-384 (in Chinese with English abstract)

[14] Zuo X-X(左晓旭), Bao G-L(鲍根良), Wang J-M(王俊敏), Luo R-T(骆荣挺), Tomita K. Comparison of grain quality between compact and loose panicle type of japonica rice. $J$ Plant Genet Resour (植物遗传资源学报), 2005, 6(2): 216-220 (in Chinese with English abstract)

[15] Xu Z-J(徐正进), Chen W-F(陈温福), Zhang L-B(张龙步), Yang $\mathrm{S}-\mathrm{R}$ (杨守仁). Advance in estimation and utilization of rice erect panicle. J Shenyang Agric Univ (沈阳农业大学学报), 1995, 26(4): 335-341 (in Chinese with English abstract)

[16] Wang F, Chen S, Cheng F, Liu Y, Zhang G. The differences in grain weight and quality within a rice (Oryza sativa L.) panicle as affected by panicle type and source-sink relation. J Agron Crop Sci, 2007, 193: 63-73

[17] Kato T. Effect of spikelet removal on the grain filling of Akenohoshi, a rice cultivar with numerous spikelets in a panicle. $J$ Agric Sci, 2004,142: 177-181

[18] Wang F, Cheng F M, Zhang G P. The relationship between grain filling and hormone content as affected by genotype and source-sink relation. Plant Growth Regul, 2006, 49: 1-8

[19] Yang J C, Zhang J H, Wang Z Q, Liu K, Wang P. Post-anthesis development of inferior and superior spikelets in rice in relation to abscisic acid and ethylene. $J$ Exp Bot, 2006, 57: 149-160

[20] Chaudhry F M, Nagato K. Role of vascular bundles in ripening of rice kernel in relation to the locations on panicle. Proc Crop Sci Jpn, 1970, 39: 301-309

[21] Iwasaki Y, Mae T, Makino A, Ohira K, Ojima K. Nitrogen accumulation in the inferior spikelet of rice ear during ripening. Soil Sci Plant Nutr, 1992, 38: 517-525

[22] Jongkaewwattana S, Geng S, Hill J E, Miller B C. Within-panicle variability of grain filling in rice cultivars with different maturities. J Agron Crop Sci, 1993, 171: 236-242

[23] Cheng W D, Zhang G P, Zhao G P, Yao H G, Xu H M. Variation in rice quality of different cultivars and grain positions as affected by water management. Field Crops Res, 2003, 80: 245-252

[24] Zhu Q-S(朱庆森), Cao X-Z(曹显祖), Luo Y-Q(骆亦奇). Growth analysis in the process of grain filling in rice. Acta Agron Sin (作物 学报), 1988, 14(3): 182-192 (in Chinese with English abstract)

[25] Zhang Z-J(张祖建), Wang Z-Q(王志琴), Zhu Q-S(朱庆森). Proliferation of endosperm cell and its relation to the growth of grain in rice. Acta Agron Sin (作物学报), 1998, 24 (3): 257-264 (in Chinese with English abstract)

[26] Yang J-C(杨建昌), Liu L-J(刘立军), Wang Z-Q(王志琴), Lang Y-Z(郎有忠), Zhu Q-S(朱庆森). Effects of flowering time of spikelets on endosperm development in rice and its physiological mechanism. Sci Agric Sin (中国农业科学), 1999, 32 (3): 44-51 (in Chinese with English abstract)

[27] Patrick J W. Phloem unloading: sieve element unloading and post-sieve element transport. Annu Rev Plant Physiol Plant Mol Biol, 1997, 48: 191-222

[28] Yang J C, Peng S B, Zhang Z J, Wang Z Q, Visperas R M, Zhu Q S. Grain and dry matter yields and partitioning of assimilates in japonica/indica hybrid rice. Crop Sci, 2002, 42: 766-772

[29] Kende H, Zeevaart J A D. The five "classical” plant hormones. Plant Cell, 1997, 9: 1197-1210

[30] Hansen H, Grossmann K. Auxin-induced enthylene triggers abscisic acid biosynthesis and growth inhibition. Plant Physiol, 2000, 124: 1437-1448

[31] Yang J C, Peng S B, Visperas R M, Sanico A L, Zhu Q S, Gu S L. Grain filling pattern and cytokinin content in the grains and roots of rice plants. Plant Growth Regul, 2000, 30: 261-270

[32] Yang J C, Zhang J H, Wang Z Q, Zhu Q S. Hormones in the grains in relation to sink strength and postanthesis development of spikelets in rice. Plant Growth Regul, 2003, 41: 185-195

[33] Yang J-C(杨建昌), Peng S-B(彭少兵), Gu S-L(顾世梁), Visperas R M, Zhu Q-S(朱庆森). Changes in activities of three enzymes associated with starch synthesis in rice grains during grain filling. Acta Agron Sin (作物学报), 2001, 27(2): 157-164 (in Chinese with English abstract)

[34] Zhao B-H(赵步洪), Zhang W-J(张文杰), Chang E-H(常二华), Wang Z-Q(王志琴), Yang J-C(杨建昌). Changes in activities of the key enzymes related to starch synthesis in rice grains during grain filling and their relationships with the filling rate and cooking quality. Sci Agric Sin (中国农业科学), 2004, 37(8): 1123-1129 (in Chinese with English abstract)

[35] Umemoto T, Nakamura Y, Ishikura N. Effect of grain location on the panicle on activities involved in starch synthesis in rice endosperm. Phytochemistry, 1994, 36: 843-847

[36] Tsutomu I, Tatsuro H, Toshiaki M, Akitoshi G, Kazunari T, Haruto S, Tomio T, Ryu-ichi I, Ryu O, Tohru Y. Expression patterns of genes encoding carbohydrate-metabolizing enzymes and their relationship to grain filling in rice (Oryza sativa L.): Comparison of caryopses located at different positions in a panicle. Plant Cell Physiol, 2005, 46: 620-628

[37] Xu Z-J(徐正进), Chen W-F(陈温福), Sun Z-H(孙占惠), Zhang S-L(张树林), Liu L-X(刘丽霞), Zhou S-Q(周淑清). Distribution of rice grains on panicle axis and its relationships with seed-setting ability in Liaoning. Sci Agric Sin (中国农业科学), 2004, 37(7): 963-967 (in Chinese with English abstract)

[38] Xu Z-J(徐正进), Chen W-F(陈温福), Zhang S-L(张树林), Zhang W-Z(张文忠), Ma D-R(马殿荣), Liu L-X(刘丽霞), Zhou $\mathrm{S}-\mathrm{Q}$ (周淑清). Differences of panicle trait index among varieties and its relationship with yield and quality of rice in Liaoning. Sci Agric Sin (中国农业科学), 2005, 38(9): 1926-1930 (in Chinese with English abstract)

[39] Xu Z-J(徐正进), Chen W-F(陈温福), Han Y(韩勇), Shao G-J(邵 国军),Zhang W-Z(张文忠), Ma D-R(马殿荣). Classification of panicle type and its relationship with grain yield and quality of rice in Liaoning province. Acta Agron Sin (作物学报), 2007, 33(9): 1411-1418 (in Chinese with English abstract)

[40] Hushibuchi K Y. Rice Breeding of Japan. Tokyo: Society of Agricultural Technology, 1992. pp 182-184 (in Japanese)

[41] Chen N(陈能), Luo Y-K(罗玉坤), Zhu Z-W(朱智伟). Correlation between eating quality and physical-chemical properties of high quality rice. Chin J Rice Sci (中国水稻科学), 1997, 11 (2): 70-76 (in Chinese with English abstract) 